Working Paper/Document de travail 2010-30

\title{
On Fiscal Multipliers: Estimates from a Medium Scale DSGE Model
}

by Sarah Zubairy 
Bank of Canada Working Paper 2010-30

November 2010

\title{
On Fiscal Multipliers: Estimates from a Medium Scale DSGE Model
}

\author{
by \\ Sarah Zubairy \\ Canadian Economic Analysis Department \\ Bank of Canada \\ Ottawa, Ontario, Canada K1A OG9 \\ szubairy@bankofcanada.ca
}

Bank of Canada working papers are theoretical or empirical works-in-progress on subjects in economics and finance. The views expressed in this paper are those of the author.

No responsibility for them should be attributed to the Bank of Canada. 


\section{Acknowledgements}

I am especially indebted to Stephanie Schmitt-Grohé and Barbara Rossi for their guidance, support and encouragement. I would also like to thank Francesco Bianchi, Craig Burnside, Marco Del Negro, Gauti Eggertsson, Cosmin Ilut, Kent Kimbrough, Juan Rubio-Ramirez and Andrea Tambalotti for helpful discussions, and seminar participants at Duke University and the Federal Reserve Bank of New York for useful comments. Part of this paper was completed while I was visiting the New York Fed, and their hospitality is gratefully acknowledged. 


\begin{abstract}
This paper contributes to the debate on fiscal multipliers, in the context of a structural model. I estimate a micro-founded dynamic stochastic general equilibrium model, that features a rich fiscal policy block and a transmission mechanism for government spending shocks, using Bayesian techniques for US data. I find the multiplier for government spending to be 1.12 , and the maximum impact is when the spending shock hits the economy. In addition, the estimated model predicts a positive but small response of private consumption to increased government spending. The multipliers for labor and capital tax on impact are 0.13 and 0.33 , respectively. The effects of tax cuts, on the other hand, take time to build, and exceed the stimulative effects of higher spending at horizons of 12-20 quarters. The expansionary effects of tax cuts are primarily driven by the response of investment. I carry out several counterfactual exercises to show how alternative financing methods and expected monetary policy have consequences for the size of fiscal multipliers. I also simulate the impact of the American Recovery and Reinvestment Act of 2009 in the estimated model.
\end{abstract}

JEL classification: C11, E32, E62, H30

Bank classification: Fiscal policy; Economic models

\title{
Résumé
}

La présente étude contribue au débat sur les multiplicateurs budgétaires dans le cadre d'un modèle structurel. L'auteure estime un modèle d'équilibre général dynamique et stochastique aux fondements microéconomiques, qui comporte un riche ensemble de règles de politique budgétaire et un mécanisme de transmission des variations des dépenses publiques, en utilisant des techniques bayésiennes sur des données relatives aux États-Unis. Les résultats obtenus indiquent que le multiplicateur des dépenses publiques s'établit à 1,12 et que l'incidence maximale a lieu au moment où le choc de dépense frappe l'économie. En outre, le modèle estimé prédit une réaction positive mais faible de la consommation privée à la hausse des dépenses publiques. Les multiplicateurs de l'impôt sur le revenu du travail et de l'impôt sur le capital au moment du choc sont respectivement de 0,13 et de 0,33. Les réductions d'impôt, en revanche, mettent du temps à faire sentir leurs effets, et elles sont plus stimulantes que les augmentations des dépenses à un horizon de 12 à 20 trimestres. Leur action expansionniste est principalement attribuable à la réaction de l'investissement. L'auteure procède à plusieurs simulations contrefactuelles afin de montrer en quoi le recours à d'autres modes de financement et la politique monétaire attendue ont des conséquences pour la taille des multiplicateurs budgétaires. Elle simule également l'incidence de la loi des États-Unis intitulée American Recovery and Reinvestment Act of 2009 dans le modèle estimé.

Classification JEL : C11, E32, E62, H30

Classification de la Banque : Politique budgétaire; Modèles économiques 


\section{Introduction}

In the current economic crisis, countries around the world have taken extraordinary fiscal measures in order to stimulate their economies with the hope of boosting demand and limiting job losses. For instance, in February 2009, the United States passed a $\$ 787$ billion American Recovery and Reinvestment Act, which amounts to over $5 \%$ of annual GDP. These policy actions, however, have given rise to a heated debate since there is a lack of consensus among economists on the relative stabilizing effects of fiscal policy measures in the form of current tax cuts or increases in spending. The objective of this paper is to shed light on this debate in the context of a micro-founded mediumscale dynamic stochastic general equilibrium (DSGE) model developed and estimated to explain the effects of discretionary fiscal policy.

The model considered in this paper features a rich fiscal block with distortionary labor and capital income taxes and a careful modeling of the government financing behavior. Unlike monetary policy, since there is no widely accepted specification for fiscal policy, this paper considers various fiscal rules, allowing fiscal variables to respond to the state of the economy and the level of government debt. Ultimately, the focus is on how the economy responds to fiscal policy actions in the form of changes in government spending, tax rates and lump-sum transfers.

In addition, the model features a transmission mechanism for government spending shocks, motivated by the fact that most commonly used business cycle models are not appropriate to study the effects of public spending shocks. As shown in the seminal paper by Baxter and King (1993), when government spending financed by lump-sum taxes rises, households face a negative wealth effect and inevitably lower their consumption and increase hours worked. The increase in labor supply also causes real wages to fall. This is, however, contrary to the findings of empirical studies that use structural vector autoregressions (VARs) to identify government spending shocks (e.g. Blanchard and Perotti (2002), Fatas and Mihov (2001)), and find consumption and wages rising in response to increased government consumption. ${ }^{1}$ In order to allow for a channel of transmission of government spending shocks, I consider a model which embeds deep habit formation in public and private consumption, as introduced in Ravn, Schmitt-Grohe, and Uribe (2006). Deep habits imply that agents form habits over individual varieties of goods, as opposed to a composite consumption good. This new feature gives rise to counter-cyclical markups, allowing wages to rise in response to a government spending shock. If this increase is large enough, it induces households to substitute away from leisure to consumption, which can potentially overcome the negative wealth effects. ${ }^{2}$

As recent public debates have revealed, there is no consensus among economists on the size

\footnotetext{
${ }^{1}$ Empirical studies employing different identification schemes, e.g Edelberg, Eichenbaum, and Fisher (1999), Burnside, Eichenbaum, and Fisher (2004) and Mountford and Uhlig (2002) find an insignificant response of consumption and also do not find private consumption crowded out by government consumption. On the other hand, Ramey and Shapiro (1998) and Ramey (2008) argue that anticipated changes in spending driven by military expenditures reduce private consumption.

${ }^{2}$ Zubairy (2009) shows that a medium scale model with lump-sum taxes, when augmented with deep habits, is able to successfully explain the effects of government spending shocks on most macroeconomic variables. That paper, however, estimates the model using a limited information approach of matching impulse response functions and does not consider distortionary taxes.
} 
of fiscal multipliers, which summarize the effects of a fiscal policy action on GDP. The need to study fiscal policy and its propagation through the economy in the context of a structural model arises since pre-existing works on fiscal multipliers employ very different identification schemes. This makes it difficult to compare the resulting multiplier estimates. For instance, Blanchard and Perotti (2002) identify government and tax shocks based on the automatic response of fiscal variables to the state of the economy relying on high frequency data at quarterly level and find a spending multiplier for output in the neighborhood of 1 and a tax multiplier of 0.7 on impact. ${ }^{3}$ Mountford and Uhlig (2002) use economic theory and econometric techniques to show that the tax multiplier is 0.19 and the spending multiplier is 0.44 on impact but the tax multiplier is significantly larger than the spending multiplier for longer horizons. Romer and Romer (2007), in a narrative study of tax changes find that the exogenous tax changes of $1 \%$ of GDP causes a slow on impact but steadily growing contractionary response of GDP and the estimated maximum impact is a fall of $3 \%{ }^{4}$ Identification of fiscal shocks is in general complicated due to difficulties in isolating exogenous movements in fiscal variables, that are not simply an automatic response to the economy and also due to lags in implementation. Leeper, Walker, and Yang (2008) point out that small fiscal VARs, employed in empirical identification of fiscal shocks, assign an information set to the econometrician that is strictly smaller than the information set on which agents base their decisions, and so could also lead to biased results for impulse response functions. Also, these VARs generally do not impose the government intertemporal budget constraint or consider fiscal financing decisions. ${ }^{5}$

In this paper, I undertake a likelihood-based Bayesian estimation of a structural model. This full-information approach fits the model to all the variation in the data, and not just dynamic effects of a policy shock. Along with standard macroeconomic aggregate variables, I also use fiscal variables as observable. These include data on government spending, and time series for labor and capital tax rates, which further allow the model to distinguish between the effects of the two different kinds of tax changes. Using Bayesian techniques I can also find the whole posterior distributions of the fiscal multipliers, which are more informative than just point estimates.

The paper reports the implied multipliers for all the fiscal instruments in the estimated model and shows how the fiscal shocks transmit through the economy. The main results can be summarized as follows: The multiplier for government spending is found to be 1.12. This means that a 1 percent of GDP increase in government spending increases GDP overall by 1.12 percent. The multiplier is larger than 1 since the estimated model predicts a positive response of private consumption to government spending, which is in contrast to models that do not consider a channel of transmission of government spending shocks, but is consistent with other empirical studies. The multipliers for labor and capital tax on impact are much smaller. A cut in tax revenues of 1 percent of GDP, driven

\footnotetext{
${ }^{3}$ Gali, Lopez-Salido, and Valles (2007) also find numbers close to 1 for spending multipliers using a similar identification scheme.

${ }^{4}$ Mertens and Ravn (2008) use the narrative evidence of Romer and Romer (2007) to distinguish between anticipated and unanticipated tax shocks and suggest that output contracts in response to an anticipation of future tax cuts but booms in reaction to implemented tax cuts.

${ }^{5}$ Chung and Leeper (2007) and Favero and Giavazzi (2007) take debt considerations into a VAR and find that omitting a debt feedback can result in incorrect estimates of the dynamic effects of fiscal shocks.
} 
by labor and capital taxes cause GDP to increase by 0.13 and 0.33 percent, respectively. However, in contrast to increased spending which has the maximum impact as soon as the shock hits the economy, the effects of tax shocks take time to build. The stimulative effects of tax cuts exceed the effects of higher spending at horizons of 12-20 quarters and are primarily driven by the response of investment. These results also highlight the fact that multipliers vary significantly across the horizon and thus the stimulative effect in the short-run differs from effects in the longer-run.

This estimated model provides an empirical framework to critically evaluate different fiscal policies. In counterfactual exercises, I examine how alternative financing decisions alter the size of multipliers and the role that automatic stabilizers play in determining the stimulative effect of spending. The results indicate that while the multipliers are mostly unaffected at shorter horizons of up to a year, the method of financing, either by increased deficits or raising taxes more aggressively is important for longer-run consequences.

I also provide evidence on how expected monetary policy have consequences for the stimulative effects of fiscal measures. The interaction between monetary and fiscal policy has recently gained significant attention, particularly in understanding the consequences of fiscal policy action under current circumstances when nominal interest rates are near zero. See for example Christiano, Eichenbaum, and Rebelo (2009), Cogan, Cwik, Taylor, and Wieland (2009), Davig and Leeper (2009) and Eggertsson (2009). The results in this paper are complementary. I find that the response of the monetary authority to deviations of output from steady state has significant effects on the size of fiscal multipliers. In fact, if the monetary authority is relatively accommodative, then increased spending has a significantly higher stimulative effect.

Lastly, I simulate the impact of the American Recovery and Reinvestment Act of 2009 in the estimated model, as a combination of increased government spending and a cut in labor taxes. This fiscal stimulus plan results in a considerable expansion in GDP, with the largest effects predicted in early 2010. These effects on output, however are accompanied by a significant rise in government debt, and since the households are forward-looking and anticipate higher taxes in the future to finance this plan, the stimulative effects on GDP decline rapidly over the course of next few years.

This paper is related to earlier work by Coenen and Straub (2005), Lopez-Salido and Rabanal (2006) and Forni, Monteforte, and Sessa (2009). These papers estimate a model of fiscal policy that extends the work of Gali, Lopez-Salido, and Valles (2007), and feature a fraction of the population being liquidity constrained in order to match the empirical evidence on the effects of government spending shocks. ${ }^{6}$ However, in contrast to this paper, the focus in the aforementioned papers has primarily been to see if the estimated model can reconcile the positive response of aggregate consumption to government spending. They do not explore detailed fiscal rules or consider the consequences of alternative financing methods and expected monetary policy on fiscal multipliers.

\footnotetext{
${ }^{6}$ Along with sticky prices, Gali, Lopez-Salido, and Valles (2007) model non-competitive behavior in labor markets and a fraction of the economy consisting of rule-of-thumb consumers who can not borrow and save, and consume their entire current income each period. In response to a government spending shock, price rigidities leads to a rise in wages which causes credit constrained consumers to raise their consumption. If a large fraction of all consumers in the economy are assumed to be credit constrained, they get a positive response for aggregate consumption to a government spending shock.
} 
The rest of the paper is organized as follows: Section 2 describes the theoretical model. In Section 3, I provide the description of the estimation procedure used. Section 4 presents the estimation results and model dynamics and Section 5 highlights the fiscal multipliers implied by the estimates. Section 6 shows some counterfactual exercises to consider alternative financing decisions. In Section 7, I explore the interaction between monetary and fiscal policy. Section 8 shows the simulation of the American Recovery and Reinvestment Act of 2009 and finally, Section 9 concludes.

\section{Model}

This is a medium scale DSGE model based on the work of Christiano, Eichenbaum, and Evans (2005). Most features are standard to the literature, such as nominal rigidities in the form of price and wage stickiness, and real rigidities in the form of variable capacity utilization and investment adjustment cost. This framework serves as a starting point since it has been shown to fit the data well, for example by Del-Negro, Schorfheide, Smets, and Wouters (2005) and Smets and Wouters (2007). The specific departures include deep habits in public and private consumption, as first introduced in Ravn, Schmitt-Grohe, and Uribe (2006), as a transmission mechanism for government spending shocks and a detailed fiscal block.

\section{$2.1 \quad$ Households}

The economy is populated by a continuum of identical households of measure one indexed by $j \in$ $[0,1]$. Each household $j \in[0,1]$ maximizes lifetime utility function, which depends on consumption, $x_{t}^{c}$, hours worked, $h_{t}$ and government provided goods, $x_{t}^{g}$, given by

$$
E_{0} \sum_{t=0}^{\infty} \beta^{t} d_{t}\left\{U\left(x_{t}^{c, j}, h_{t}^{j}\right)+V\left(x_{t}^{g}\right)\right\} .
$$

In this formulation, $d_{t}$ is an intertemporal preference shock, or a shock to consumer's impatience level and affects both the marginal utility of consumption and marginal disutility of labor. It follows an autoregressive process, ${ }^{7}$

$$
\hat{d}_{t}=\rho_{d} \hat{d}_{t-1}+\epsilon_{t}^{d}
$$

where $\rho^{d} \in[0,1]$ is the autoregressive coefficient, and $\epsilon_{t}^{d}$ is i.i.d $N\left(0, \sigma_{d}^{2}\right)$. Households derive utility from consumption of government provided goods, given by $x_{t}^{g}$ here, which is separable from private consumption and leisure. This means that public spending does not affect the marginal utility of private consumption or leisure. ${ }^{8}$

\footnotetext{
${ }^{7}$ Throughout the paper, a hatted variable represents log deviations from its steady state.

${ }^{8}$ This is a common assumption in the literature, and studies such as Aschauer (1985), Ni (1995) and McGrattan (1994) who examine whether in fact private and public consumption are substitutes or complements find mixed and inconclusive results.
} 
The variable $x_{t}^{c}$ is a composite of habit adjusted consumption of a continuum of differentiated goods indexed by $i \in[0,1]$,

$$
x_{t}^{c, j}=\left[\int_{0}^{1}\left(c_{i t}^{j}-b^{c} s_{i t-1}^{C}\right)^{1-\frac{1}{\eta}} d i\right]^{1 /\left(1-\frac{1}{\eta}\right)},
$$

where $s_{i t-1}^{C}$ denotes the stock of habit in consuming good $i$ in period $t$, the parameter $\eta$ is the elasticity of substitution between intermediate goods. The parameter $b^{c} \in[0,1)$ measures the degree of external habit formation, and when $b^{c}$ is zero, the households do not exhibit deep habit formation. The stock of external habit is assumed to depend on a weighted average of consumption in all past periods. Habits are assumed to evolve over time according to the law of motion,

$$
s_{i t}^{C}=\theta^{c} s_{i t-1}^{C}+\left(1-\theta^{c}\right) c_{i t} .
$$

The parameter $\theta^{c} \in[0,1)$ measures the speed of adjustment of the stock of external habit to variations in the cross-sectional average level of consumption of variety $i$. When $\theta^{c}$ takes the value zero, habit is measured by past consumption. This slow decay in habit allows for persistence in markup movements.

For any given level of consumption $x_{t}^{c, j}$, purchases of each individual variety of good $i \in[0,1]$ in period $t$ solves the dual problem of minimizing total expenditure, $\int_{0}^{1} P_{i t} c_{i t} d i$, subject to the aggregation constraint (3), where $P_{i t}$ denotes the nominal price of a good of variety $i$ at time $t$. The optimal level of $c_{i t}^{j}$ for $i \in[0,1]$ is then given by

$$
c_{i t}^{j}=\left(\frac{P_{i t}}{P_{t}}\right)^{-\eta} x_{t}^{c, j}+b^{c} s_{i t-1}^{C},
$$

where $P_{t}$ is a nominal price index defined as

$$
P_{t} \equiv\left[\int_{0}^{1} P_{i t}^{1-\eta} d i\right]^{\frac{1}{1-\eta}} .
$$

Note that consumption of each variety is decreasing in its relative price, $P_{i t} / P_{t}$ and increasing in level of habit adjusted consumption $x_{t}^{c, j}$. The demand function in equation (5) has a price-elastic component that depends on aggregate consumption demand, and the second term is perfectly priceinelastic. An increase in aggregate demand increases the share of the price-elastic component, and thus increases the elasticity of demand, inducing a decline in the mark-up. In addition to this, firms also take into account that today's price decisions will affect future demand, as is apparent due to $s_{i t-1}$ term, and so when the present value of future per unit profit are expected to be high, firms have an incentive to invest in the customer base today. Thus, this gives them an additional incentive to appeal to a broader customer base by reducing markups in the current period. This countercyclicality of the price markup has been empirically documented by Bils (1987), Rotemberg 
and Woodford (1999) and Gali, Gertler, and Lopez-Salido (2007) among others. ${ }^{9}$

Each household $j$ is a monopolistic provider of a differentiated labor service, and is assumed to supply enough labor, $h_{t}^{j}$, to satisfy demand,

$$
h_{t}^{j}=\left(\frac{w_{t}^{j}}{w_{t}}\right)^{-\tilde{\eta}} h_{t}
$$

where $w_{t}^{j} \equiv W_{t}^{j} / P_{t}$ and $w_{t} \equiv W_{t} / P_{t} . W_{t}^{j}$ denotes the nominal wage charged by household $j$ at time $t, W_{t}$ is an index of nominal wages prevailing in the economy, and $h_{t}$ is a measure of aggregate labor demand by firms. The parameter $\tilde{\eta}$ is the elasticity of substitution between differentiated labor types. In addition, wage rigidities are modeled as a convex cost of adjusting nominal wages which is zero at steady state. The real total adjustment cost for household $j$ is given by, $\frac{\tilde{\alpha}}{2}\left(\frac{P_{t} w_{t}^{j}}{P_{t-1} w_{t-1}^{j}}-\bar{\pi}\right)^{2}$, where $\tilde{\alpha}$ denotes the wage adjustment cost parameter.

The household is assumed to own physical capital, $k_{t}$, which accumulates according to the following law of motion,

$$
k_{t+1}^{j}=(1-\delta) k_{t}^{j}+i_{t}^{j}\left[1-\mathcal{S}\left(\mu_{t} \frac{i_{t}^{j}}{i_{t-1}^{j}}\right)\right],
$$

where $i_{t}^{j}$ denotes investment by household $j$ and $\delta$ is a parameter denoting the rate of depreciation of physical capital. The function $\mathcal{S}$ introduces investment adjustment costs and has the following functional form, $\mathcal{S}\left(\mu_{t} \frac{i_{t}}{i_{t-1}}\right)=\frac{\kappa}{2}\left(\mu_{t} \frac{i_{t}}{i_{t-1}}-1\right)^{2}$, and therefore in the steady state it satisfies $\mathcal{S}=$ $\mathcal{S}^{\prime}=0$ and $\mathcal{S}^{\prime \prime}>0$. These assumptions imply the absence of adjustment costs up to first-order in the vicinity of the deterministic steady state. Here, $\mu_{t}$ denotes an efficiency shock to the investment adjustment cost. It also follows an autoregressive process given by

$$
\hat{\mu}_{t}=\rho_{\mu} \hat{\mu}_{t-1}+\epsilon_{t}^{\mu}
$$

where $\rho^{\mu} \in[0,1]$ is the autoregressive coefficient, and $\epsilon_{t}^{\mu}$ is i.i.d $N\left(0, \sigma_{\mu}^{2}\right)$.

Owners of physical capital can control the intensity at which this factor is utilized. Formally, let $u_{t}$ measure capacity utilization in period $t$. It is assumed that using the stock of capital with intensity $u_{t}$ entails a cost of $a\left(u_{t}\right) k_{t}$ units of the composite final good. ${ }^{10}$ Households rent the capital stock to firms at the real rental rate $r_{t}^{k}$ per unit of capital. Total income stemming from the rental of capital is given by $r_{t}^{k} u_{t} k_{t}$.

\footnotetext{
${ }^{9}$ Monacelli and Perotti (2008), in fact, also show this fall in the markup in response to a demand shock in the form of increased government spending, in a structural VAR.

${ }^{10}$ In steady state, $u$ is set to be equal to 1 , and so $a(u)=0$. During the estimation, $a^{\prime \prime}(1) / a^{\prime}(1)=\sigma_{u}$ is estimated, which determines dynamics.
} 
The household's period-by-period budget constraint is given by

$$
\begin{aligned}
E_{t} r_{t, t+1} a_{t+1}^{j}+ & x_{t}^{c, j}+\omega_{t}^{j}+i_{t}^{j}+a\left(u_{t}^{j}\right) k_{t}^{j}+w_{t} \frac{\tilde{\alpha}}{2}\left(\frac{w_{t}^{j}}{w_{t-1}^{j}} \pi_{t}-\bar{\pi}\right)^{2} \\
& =\frac{a_{t}^{j}}{\pi_{t}}+\left(1-\tau_{t}^{k}\right) r_{t}^{k} u_{t}^{j} k_{t}^{j}+\left(1-\tau_{t}^{w}\right) w_{t}^{j} h_{t}^{j}+\delta q_{t} \tau_{t}^{k} u_{t}^{j} k_{t}^{j}+t r_{t}^{j}+\phi_{t}^{j}
\end{aligned}
$$

where $\omega_{t}=b^{c} \int_{0}^{1} P_{i t} s_{i t-1}^{C} / P_{t} d i$. The variable $a_{t} / \pi_{t} \equiv A_{t} / P_{t}$ denotes the real payoff in period $t$ of nominal state-contingent assets purchased in period $t-1$. The variable $\phi_{t}$ denotes dividends received from the ownership of firms and $\pi_{t} \equiv P_{t} / P_{t-1}$ denotes the gross rate of consumer-price inflation. The households face labor and capital income tax rates, given by $\tau_{t}^{w}$ and $\tau_{t}^{k}$ respectively, and get a lump-sum transfer from the government, given by $t r_{t}$. The term $\delta q_{t} \tau_{t}^{k} u_{t} k_{t}$ represents a depreciation allowance for tax purposes. ${ }^{11}$

Each household chooses processes for $x_{t}^{c, j}, h_{t}^{j}, a_{t+1}^{j}, w_{t}^{j}, k_{t+1}^{j}, i_{t}^{j}$, and $u_{t}^{j}$ in order to maximize the utility function subject to (6), (7), (9) and the standard no-Ponzi-game constraint, taking as given the processes for $\omega_{t}, w_{t}, r_{t}^{k}, r_{t, t+1}, \pi_{t}, \phi_{t}, \tau_{t}^{k}, \tau_{t}^{w}$ and $t r_{t}$ and the initial conditions $a_{0}^{h}$ and $k_{0}$.

\subsection{Fiscal and Monetary Policy}

Similar to households, the government is also assumed to form habits on consumption of individual varieties of goods. Recalling the expression in (1), households also derive utility from public goods. Utility over public consumption is assumed to be separable from private consumption and leisure, and the households also form external habits over these public goods. As motivated in Ravn, Schmitt-Grohe, and Uribe (2007), the provision of public services in one community, such as street lighting or garbage collection, creates other communities to also want access to those public services. Otherwise, this can also be thought of as the government favoring transactions with procurement contractors from whom they have purchased public goods in the past.

The government allocates spending over individual varieties of goods, $g_{i t}$, so as to maximize the quantity of a composite good, $x_{t}^{g}$, produced with a differentiated varieties of goods according to the following relation,

$$
x_{t}^{g}=\left[\int_{0}^{1}\left(g_{i t}-b^{g} s_{i t-1}^{G}\right)^{1-1 / \eta}\right]^{1 /(1-1 / \eta)} .
$$

The parameter $b^{g}$ measures the degree of habit formation of government consumption and the variable $s_{i t}^{G}$ denotes the government's stock of habit in good $i$ and is assumed to evolve as follows,

$$
s_{i t}^{G}=\theta^{g} s_{i t-1}^{G}+\left(1-\theta^{g}\right) g_{i t},
$$

where $\theta^{g}$ is the rate of depreciation of the stock of habits. The government's problem consists of

\footnotetext{
${ }^{11}$ This is because part of the payment that capital owners receive from renting out their capital stock merely reflects compensation for the stocks depreciation. Therefore, this component of revenue is not income, and so should not be subject to taxation. In practice, depreciation expenses are tax deductible.
} 
choosing $g_{i t}, i \in[0,1]$, so as to maximize $x_{t}^{g}$ subject to the budget constraint $\int_{0}^{1} P_{i t} g_{i t} \leq P_{t} g_{t}$, taking as given the initial condition $g_{i t}=g_{t}$, where $g_{t}$ denotes real government expenditures. The resulting demand function for each differentiated good $i \in[0,1]$ by the public sector is

$$
g_{i t}=\left(\frac{P_{i t}}{P_{t}}\right)^{-\eta} x_{t}^{g}+b^{g} s_{i t-1}^{G}
$$

which is analogous to the demand function for household consumption. Therefore, introducing deep habits in public consumption, along with private consumption, is needed to generate countercyclical markups in response to both an increase in private and public consumption demand.

The fiscal authority issues bonds, $b_{t}$ and raises tax revenues, $\tau_{t}$ and the expenditures include government purchases, $g_{t}$ and lump-sum transfers to households, $t r_{t}$. The government budget constraint looks as follows,

$$
b_{t}=R_{t-1} \frac{b_{t-1}}{\pi_{t}}+g_{t}+t r_{t}-\tau_{t}
$$

where tax revenues, $\tau_{t}$ are given by,

$$
\tau_{t}=\tau_{t}^{w} w_{t} h_{t}+\tau_{t}^{k}\left(r_{t}^{k} u_{t} k_{t}-\delta q_{t} u_{t} k_{t}\right)
$$

Unlike monetary policy, there is no widely accepted specification for fiscal policy. For instance, in earlier work, McGrattan (1994) introduces reduced form fiscal rules with a VAR representation of exogenous state variables, namely technology shocks, government spending and tax rates. Braun (1994) also runs a VAR for government spending and tax rates, and after dropping insignificant coefficients settles on AR(1) processes for both spending and taxes. Leeper (1991) has a fiscal rule with taxes responding to the level of real outstanding government debt, and Schmitt-Grohe and Uribe (2007) show that such rules can approximate optimal policy rules. Jones (2002) has a reduced form representation where tax and spending rates are functions of their own lags, current and lagged output and current and lagged hours, to reflect the notion that policymakers care about output and employment. He also distinguishes between the effects of exogenous fiscal shocks and effects of feedback rules. Mertens and Ravn (2008) assume stochastic AR(2) processes for tax rates, and allow no feedback from the economy. However, they distinguish between anticipated and unanticipated tax shocks.

In recent work, Romer and Romer (2007) use narrative evidence to identify the size and reasons behind all major postwar tax policy actions. They find tax policy actions as either being motivated by counter-cyclical actions or changes in spending, which they call endogenous policy changes, or tax changes in order to deal with an inherited budget deficit or raise long-run growth, classified as exogenous changes in their analysis. They estimate the effects of exogenous tax movements on output and point out that failing to account for influences of economic activity on tax policy leads to biased effects of macroeconomic effects of tax changes. ${ }^{12}$ In order to address such concerns, in this paper, taxes are modeled to allow for automatic stabilizers by responding to the state of

\footnotetext{
${ }^{12}$ Leeper, Walker, and Yang (2009) also emphasize endogeneity of tax policy.
} 
the economy and feedback reaction to debt in order to prevent large debt to GDP ratios, and the processes for tax rates look as follows, ${ }^{13}$

$$
\hat{\tau}_{t}^{k}=\rho_{k} \hat{\tau}_{t-1}^{k}+\rho_{k, b} \hat{b}_{t-1}+\rho_{k, y} \hat{y}_{t-1}+\epsilon_{t}^{k}
$$

and

$$
\hat{\tau}_{t}^{w}=\rho_{w} \hat{\tau}_{t-1}^{w}+\rho_{w, b} \hat{b}_{t-1}+\rho_{w, y} \hat{y}_{t-1}+\epsilon_{t}^{w}
$$

Here $\epsilon_{t}^{k}$ and $\epsilon_{t}^{w}$ denote innovations in the two tax rates and are i.i.d $N\left(0, \sigma_{k}^{2}\right)$ and $N\left(0, \sigma_{w}^{2}\right)$, respectively. The response of the tax rates to the level of debt ensure fiscal solvency. For instance, in the case of increased government expenditures, taxes will respond to the increasing deficit so that the intertemporal government budget constraint is satisfied. Note that the tax rates are assumed to respond to lagged values of the debt and output deviations from the steady state. This helps to isolate the effects of fiscal shocks on the economy at least on impact, and is a reasonable assumption as the model is used to match quarterly data.

Real government expenditures, $g_{t}$, have a process with an autoregressive term and a response to lagged output to capture automatic stabilizers ${ }^{14}$,

$$
\hat{g}_{t}=\rho_{g} \hat{g}_{t-1}+\rho_{g, y} \hat{y}_{t-1}+\epsilon_{t}^{g}
$$

where $\epsilon_{t}^{g}$ is a government spending shock, assumed to be i.i.d $N\left(0, \sigma_{g}^{2}\right) \cdot{ }^{15}$ Lump-sum transfers, $t r_{t}$, have the following process which also features a response to the state of the economy. This captures the fact that during recessions, transfers automatically go up, for instance in the form of unemployment and welfare benefits,

$$
\hat{t r}_{t}=\rho_{t r} \hat{t r}_{t-1}+\rho_{t r, y} \hat{y}_{t-1}+\epsilon_{t}^{t r}
$$

where $\epsilon_{t}^{t r}$ represents a shock to transfers, and is i.i.d $N\left(0, \sigma_{t} r^{2}\right)$. Transfers are modeled as neutral payments in the model, and primarily play the role of a residual in the government budget constraint. So a transfer shock can be thought of as a shock to the budget constraint, not captured by spending or tax shocks. ${ }^{16}$

\footnotetext{
${ }^{13}$ The fiscal rules are specified in terms of taxes and expenditures. However, these fiscal rules together with the government's budget constraint imply an evolution process of debt or deficit, which at times seems the main policy instrument in public debates.

${ }^{14}$ There is not as much empirical evidence for automatic stabilizers in the case of government spending, see for instance Blanchard and Perotti (2002), but during the estimation, I assume $\rho_{g, y}$ to have a normal distribution allowing for the possibility of a pro-cyclical or counter-cyclical component of public spending on consumption and investment.

${ }^{15}$ Preliminary analysis during estimation did not yield evidence for government spending significantly responding to the level of debt and hence is not considered here. However, in a recent paper with calibration, Corsetti, Meier, and Muller (2009) model government spending to respond to the level of debt, and show that this causes an eventual reversal of spending and can explain consumption rising in response to a government spending shock. Leeper, Plante, and Traum (2009) also allow government spending to respond to the level of debt, in a real model studying fiscal financing.

${ }^{16}$ The Appendix reports how alternative modeling assumptions for government spending and transfers compare to this specification, in terms of marginal likelihood. These specifications include exogenous process for transfers and
} 
The monetary authority follows a Taylor type rule,

$$
\hat{R}_{t}=\alpha_{R} \hat{R}_{t-1}+\left(1-\alpha_{R}\right)\left(\alpha_{\pi} \hat{\pi}_{t}+\alpha_{Y} \hat{y}_{t}\right)+\epsilon_{t}^{m},
$$

with interest rate smoothing, governed by the parameter $\alpha_{R}$ and a response to deviation of inflation and output from their respective steady states, denoted by $\hat{\pi}$ and $\hat{y}_{t}$ respectively. $\epsilon_{t}^{m}$ is a monetary shock and is i.i.d $N\left(0, \sigma_{m}^{2}\right)$.

\section{$2.3 \quad$ Firms}

Each variety of final goods is produced by a single firm in a monopolistically competitive environment. Each firm $i \in[0,1]$ produces output using as factor inputs capital services, $k_{i t}$ and labor services, $h_{i t}$. The production technology is given by,

$$
z_{t} F\left(k_{i t}, h_{i t}\right)-\psi
$$

where $F$ is a homogenous of degree one, concave function strictly increasing in both its arguments and $\psi$ introduces fixed costs of operating a firm in each period, and are modeled to ensure a realistic profit-to-output ratio in steady state. The variable $z_{t}$ denotes an exogenous technology shock, following an $\mathrm{AR}(1)$ process,

$$
\hat{z}_{t}=\rho_{z} \hat{z}_{t-1}+\epsilon_{t}^{z}
$$

where $\rho^{z} \in[0,1]$, and $\epsilon_{t}^{z}$ is i.i.d $N\left(0, \sigma_{z}^{2}\right)$.

The objective of the firm is to choose contingent plans for $P_{i t}, h_{i t}$, and $k_{i t}$ so as to maximize the present discounted value of dividend payments, given by

$$
E_{t} \sum_{s=0}^{\infty} r_{t, t+s} P_{t+s} \phi_{i t+s}
$$

where

$$
\phi_{i t}=\frac{P_{i t}}{P_{t}} a_{i t}-r_{t}^{k} k_{i t}-w_{t} h_{i t}-\frac{\alpha}{2}\left(\frac{P_{i t}}{P_{i t-1}}-\bar{\pi}\right)^{2},
$$

subject to demand functions for public, private and investment goods faced by firm $i$. Here $a_{i t}$ denotes aggregate absorption of good $i$, which includes $c_{i t}, i_{i t}$ and $g_{i t}$. Note that price rigidities are introduced following Rotemberg (1982), by assuming that the firms face a quadratic price adjustment cost for the good it produces. I choose this specification of price rigidities because the introduction of deep habits makes the pricing problem dynamic and accounting for additional dynamics arising from Calvo-Yun type price stickiness makes aggregation non-trivial. ${ }^{17}$

spending, and also allowing transfers to respond to the level of debt.

${ }^{17}$ Modeling price stickiness via a quadratic cost leads to the same Phillips curve and dynamics up to first order as Calvo-Yun price stickiness. 


\subsection{Market Clearing}

Integrating over all firms and taking into account that the capital-labor ratio is common across firms, the aggregate demand for the composite labor input, $h_{t}$, satisfies $h_{t}=\int_{0}^{1} h_{i t} d i$, and that the aggregate effective level of capital, $u_{t} k_{t}$ satisfies $u_{t} k_{t}=\int_{0}^{1} k_{i t} d i$, this implies a resource constraint that looks as follows,

$$
z_{t} F\left(u_{t} k_{t}, h_{t}\right)-\psi=c_{t}+g_{t}+i_{t}+a\left(u_{t}\right) k_{t}+\frac{\alpha}{2}\left(\pi_{t}-\bar{\pi}\right)^{2}+\frac{\tilde{\alpha}}{2}\left(\pi_{t}^{w}-\bar{\pi}\right)^{2} w_{t} .
$$

Equilibrium marginal costs and capital-labor ratios are identical across firms. Therefore, one can aggregate the firm's optimality conditions with respect to labor and capital. The complete set of symmetric equilibrium conditions are given in the Appendix.

\section{Estimation}

The competitive equilibrium conditions of the model are log-linearized around a non-stochastic steady state. ${ }^{18}$ The system of equations can then be written as follows,

$$
x_{t}=F(\Theta) x_{t-1}+Q(\Theta) \epsilon_{t},
$$

where $x_{t}$ are the model variables, the matrices $F$ and $Q$ are functions of $\Theta$, the structural parameters of the model and $\epsilon_{t}$ are the structural shocks in the model.

\subsection{Data and Estimation Strategy}

Since the focus of this paper is fiscal policy in the context of a DSGE model, in departure from most pre-existing Bayesian estimation papers, in addition to aggregate macroeconomic variables, I include fiscal variables as observable. The following quarterly data series, spanning 1958:1-2008:4, are used in the estimation, $\left[c_{t} i_{t} \pi_{t} R_{t} g_{t} b_{t} \tau_{t}^{k} \tau_{t}^{w}\right]$, where $c_{t}$ is real per capita consumption, $i_{t}$ is real per capita investment, $\pi_{t}$ is price inflation, $R_{t}$ is the federal funds rate, $g_{t}$ is real per capita total government purchases, $b_{t}$ is real federal debt held by public, $\tau_{t}^{k}$ is the capital tax rate and $\tau_{t}^{w}$ is the labor tax rate. ${ }^{19}$ Details on the construction of each time series are provided in the Appendix.

The measurement equation connects the observables, $o b s_{t}$ to the model variables,

$$
o b s_{t}=H(\Theta) x_{t}+v_{t}
$$

The matrix $H$ is a function of the structural parameters of the model and $v_{t}$ denotes measurement errors. The dynamic system characterized by the state equation, (21) and this measurement

\footnotetext{
${ }^{18}$ The complete set of equilibrium conditions along with the steady state are given in the Appendix. The model is log-linearized and solved using the method of Schmitt-Grohe and Uribe (2004).

${ }^{19}$ The data used in the estimation starts in 1958:1, due to unavailability of property tax data prior to that date, which is used in the construction of capital tax data.
} 
equation is estimated using Bayesian techniques, where the object of interest is the joint posterior distribution of the parameters, which combines the prior distribution and the likelihood function. The priors for the parameters being estimated are given in the next subsection, and the likelihood is computed using the Kalman filter, under the assumption of all the structural shocks being normally distributed. The Metropolis-Hastings algorithm is used to sample from the posterior proposal distribution, which is a multivariate normal, $N(0, c \Sigma)$. The algorithm is initialized using the maximized posterior mode from the optimization routine csminwel.m, by Chris Sims, and $\Sigma$ is the inverse of the numerical Hessian evaluated at this posterior mode. The scaling factor $c$ is chosen to ensure an acceptance rate of close to $30 \%$. 1.5 million draws are generated, where the first 500,000 are used as burn-in period, to lose any dependence on initial values. Ultimately, several convergence diagnostics are used to ensure the convergence of these Monte Carlo chains. ${ }^{20}$

\subsection{Calibration and Priors}

Some of the parameters which are hard to identify or pin down in steady state are calibrated. These include the discount factor $\beta$, set at $1.03^{-1 / 4}$, which implies a steady-state annualized real interest rate of 3 percent. The depreciation rate, $\delta$, is set at 0.025 , which implies an annual rate of depreciation on capital equal to 10 percent. $\theta$ is set at 0.30 , which corresponds to a steady state share of capital income roughly equal to $30 \%$. The labor elasticity of substitution, $\tilde{\eta}$ is set at 21 , and goods elasticity of substitution, $\eta$ is set at 5.3, since with the introduction of deep habits the price markup movements are jointly determined by deep habit parameters and $\eta$ is generally not well identified.

Some of the steady state variables are also calibrated based on averages over the sample period considered in the paper. The share of government spending in aggregate output is set at 0.18, and the annual average of the ratio of debt to GDP pins down the steady state value to be 0.33 . Similarly, the steady state values of the capital and labor tax rates are based on mean of the constructed series of average tax rates over the sample size, and are 0.41 and 0.23 respectively. Also, the steady state labor is set at 0.5 , which corresponds to a Frisch elasticity of labor supply of unity.

Table 2 shows the prior distribution for the parameters being estimated. These are consistent with the literature and the means of the distribution were set based on estimates from pre-existing studies. The autoregressive coefficients in the shock processes have a beta distribution with a mean of 0.7 and standard deviation of 0.2 . The only exception is the government spending process which is known to be highly persistent. The priors on standard deviations of the shocks have an inverse gamma distribution and are quite disperse. The deep habit parameters are assumed to have a beta distribution and the mean is in line with estimates from Zubairy (2009), where deep habits are explored as a transmission mechanism for government spending shocks with a limited information approach. The capacity utilization and investment adjustment cost parameters have normal distributions with means of 2.5 and 2 respectively, in line with estimates from Smets and

\footnotetext{
${ }^{20}$ The diagnostics include trace plots, examining the autocorrelation functions and CUSUM plots.
} 
Table 1: Calibrated Parameters

\begin{tabular}{lll}
\hline \hline & & \\
Parameter & Description & Calibrated value \\
\hline & & \\
$\beta$ & Depreciation rate & 0.025 \\
$\tilde{\eta}$ & Discount factor & 0.9926 \\
$\eta$ & Wage elasticity of demand & 21 \\
$\theta$ & Price elasticity of demand & 5.3 \\
& Capital share & 0.30 \\
$\pi$ & & \\
$u$ & Steady state inflation & $1.042^{1 / 4}$ \\
$h$ & Steady state capacity utilization & 1 \\
$g / y$ & Steady state labor & 0.5 \\
$b / y$ & Share of govt. spending in GDP & 0.18 \\
$\tau^{k}$ & Ratio of debt to GDP (annual) & 0.33 \\
$\tau^{w}$ & Steady state capital tax rate & 0.41 \\
\multicolumn{2}{l}{ Steady state labor tax rate } & 0.23 \\
\hline
\end{tabular}

Wouters (2007) and Altig, Christiano, Eichenbaum, and Linde (2005). The coefficient of relative risk aversion $\sigma$ is assumed to have a normal distribution with a mean of 2 , which is higher than the logarithmic case. The nominal rigidity parameters have a normal distributions where the means correspond approximately with an adjustment frequency of close to four quarters, in the mapping between the Phillips curve coefficient implied by convex adjustment costs specification and the one with Calvo-Yun type rigidities. The standard deviation of these prior distributions are large to accommodate uncertainty in these parameters.

Monetary policy rule parameters have prior distributions similar to the ones adopted in Smets and Wouters (2007) and the mean values are also consistent with estimates from Clarida, Gali, and Gertler (2000). On the other hand for fiscal policy rule parameters, the literature is less informative and so the priors are diffuse and span a larger parameter space. As mentioned above, the tax rate processes are assumed to be persistent. The tax rate elasticities to debt are assumed to have a gamma distribution with a mean of 0.5 and a standard deviation of 0.2 , which is similar to Forni, Monteforte, and Sessa (2009). Blanchard and Perotti (2002) provide evidence regarding output elasticities of tax revenues, an average value of 2.08 . This would mean that with $1 \%$ increase in output, tax revenues rise by close to $2 \%$, which would roughly mean a $1 \%$ rise in tax rates. The tax rate elasticities for both tax rates are thus assumed to have a gamma distribution with mean 1 and standard deviation of 0.5. Blanchard and Perotti (2002) find no strong evidence of automatic stabilizers for government spending. Thus the government spending elasticity to output is assumed to have a normal distribution with mean -0.05 and the transfers elasticity to output is assumed to have a mean of -0.1. In order to further clarify the economic content of the priors, the Appendix shows the fiscal multipliers implied by the priors, in Table 6 . 
Table 2: Prior and Posterior Distribution of Estimated Parameters.

\begin{tabular}{|c|c|c|c|c|c|c|}
\hline \multirow[t]{2}{*}{ Parameter } & \multirow[t]{2}{*}{ Description } & \multicolumn{3}{|c|}{ Prior } & \multicolumn{2}{|c|}{ Posterior } \\
\hline & & Dist. & Mean & Std. Dev. & Mean & {$[5,95]$} \\
\hline$\rho_{k}$ & Autocorr. of $\tau_{t}^{k}$ & $\mathrm{~B}$ & 0.7 & 0.2 & 0.89 & {$[0.88,0.90]$} \\
\hline$\rho_{w}$ & Autocorr. of $\tau_{t}^{w}$ & $\mathrm{~B}$ & 0.7 & 0.2 & 0.91 & {$[0.90,0.92]$} \\
\hline$\rho_{g}$ & Autocorr. of $g_{t}$ & B & 0.8 & 0.2 & 0.92 & {$[0.89,0.93]$} \\
\hline$\rho_{d}$ & Autocorr. of $d_{t}$ & $\mathrm{~B}$ & 0.7 & 0.2 & 0.68 & {$[0.67,0.70]$} \\
\hline$\rho_{t r}$ & Autocorr. of $t r_{t}$ & B & 0.7 & 0.2 & 0.75 & {$[0.73,0.77]$} \\
\hline$\rho_{z}$ & Autocorr. of $z_{t}$ & $\mathrm{~B}$ & 0.7 & 0.2 & 0.82 & {$[0.80,0.83]$} \\
\hline$\rho_{\mu}$ & Autocorr. of $\mu_{t}$ & $\mathrm{~B}$ & 0.7 & 0.2 & 0.70 & {$[0.67,0.73]$} \\
\hline$\sigma_{k}$ & Std. Dev. of $\epsilon_{t}^{k}$ & IG & 0.5 & 1 & 0.012 & {$[0.010,0.013]$} \\
\hline$\sigma_{w}$ & Std. Dev. of $\epsilon_{t}^{w}$ & IG & 0.5 & 1 & 0.009 & {$[0.008,0.010]$} \\
\hline$\sigma_{g}$ & Std. Dev. of $\epsilon_{t}^{g}$ & $\mathrm{IG}$ & 0.5 & 1 & 0.015 & {$[0.014,0.017]$} \\
\hline$\sigma_{d}$ & Std. Dev. of $\epsilon_{t}^{d}$ & $\mathrm{IG}$ & 0.5 & 1 & 0.156 & {$[0.137,0.177]$} \\
\hline$\sigma_{t r}$ & Std. Dev. of $\epsilon_{t}^{t r}$ & $\mathrm{IG}$ & 0.5 & 1 & 0.054 & {$[0.038,0.090]$} \\
\hline$\sigma_{z}$ & Std. Dev. of $\epsilon_{t}^{z}$ & IG & 0.5 & 1 & 0.024 & {$[0.021,0.026]$} \\
\hline$\sigma_{m}$ & Std. Dev. of $\epsilon_{t}^{m}$ & $\mathrm{IG}$ & 0.5 & 1 & 0.018 & {$[0.016,0.020]$} \\
\hline$\sigma_{\mu}$ & Std. Dev. of $\epsilon_{t}^{m}$ & IG & 0.5 & 1 & 0.077 & {$[0.072,0.083]$} \\
\hline$b^{c}$ & Deep habit in $c_{t}$ & $\mathrm{~B}$ & 0.7 & 0.1 & 0.96 & {$[0.95,0.97]$} \\
\hline$\theta^{c}$ & Adj. of habit stock of $c_{t}$ & $\mathrm{~B}$ & 0.8 & 0.1 & 0.58 & {$[0.55,0.60]$} \\
\hline$b^{g}$ & Deep habit in $g_{t}$ & $\mathrm{~B}$ & 0.7 & 0.1 & 0.74 & {$[0.73,0.76]$} \\
\hline$\theta^{g}$ & Adj. of habit stock of $g_{t}$ & $\mathrm{~B}$ & 0.8 & 0.1 & 0.96 & {$[0.95,0.97]$} \\
\hline$\alpha$ & Price adj. cost & $\mathrm{N}$ & 17 & 5 & 44.07 & {$[40.5,47.7]$} \\
\hline$\tilde{\alpha}$ & Wage adj. cost & $\mathrm{N}$ & 100 & 30 & 95.40 & {$[92.4,97.7]$} \\
\hline$\sigma$ & Preference parameter & $\mathrm{N}$ & 2 & 1 & 2.12 & {$[2.01,2.33]$} \\
\hline$\sigma_{u}$ & Capacity util. parameter & $\mathrm{N}$ & 2.5 & 0.5 & 2.57 & {$[2.45,2.68]$} \\
\hline$\kappa$ & Investment adj. cost & $\mathrm{N}$ & 2 & 0.5 & 3.04 & {$[2.98,3.07]$} \\
\hline$\alpha_{R}$ & Int. rate smoothing & $\mathrm{B}$ & 0.8 & 0.2 & 0.52 & {$[0.51,0.54]$} \\
\hline$\alpha_{\pi}$ & Response of $R_{t}$ to $\pi_{t}$ & $\mathrm{~N}$ & 1.6 & 0.2 & 1.55 & {$[1.53,1.56]$} \\
\hline$\alpha_{Y}$ & Response of $R_{t}$ to $y_{t}$ & $\mathrm{~N}$ & 0.1 & 0.05 & 0.051 & {$[0.045,0.057]$} \\
\hline$\rho_{k, b}$ & Response of $\tau_{t}^{k}$ to $b_{t-1}$ & G & 0.5 & 0.25 & 0.015 & {$[0.009,0.021]$} \\
\hline$\rho_{w, b}$ & Response of $\tau_{t}^{w}$ to $b_{t-1}$ & $\mathrm{G}$ & 0.5 & 0.25 & 0.016 & {$[0.010,0.024]$} \\
\hline$\rho_{k, y}$ & Response of $\tau_{t}^{k}$ to $y_{t-1}$ & $\mathrm{G}$ & 1 & 0.5 & 0.131 & {$[0.119,0.140]$} \\
\hline$\rho_{w, y}$ & Response of $\tau_{t}^{w}$ to $y_{t-1}$ & G & 1 & 0.5 & 0.114 & {$[0.101,0.124]$} \\
\hline$\rho_{g, y}$ & Response of $g_{t}$ to $y_{t-1}$ & $\mathrm{~N}$ & -0.05 & 0.05 & -0.0032 & {$[-0.012,0.000]$} \\
\hline$\rho_{t r, y}$ & Response of $t r_{t}$ to $y_{t-1}$ & $\mathrm{~N}$ & -0.1 & 0.05 & -0.122 & {$[-0.141,-0.104]$} \\
\hline
\end{tabular}

Note: B denotes Beta, G denotes Gamma, IG denotes Inverse Gamma and N denotes Normal. 


\section{Estimation results}

\subsection{Parameter estimates}

The mean and 5 and 95 percentiles of the posterior distribution for the parameters estimated are given in Table 2. All the shocks are significantly persistent. The preference parameter, investment adjustment cost and capacity utilization parameters are estimated to be consistent with estimates in the literature. ${ }^{21}$ The degree of deep habit in private consumption is quite high, and the estimates for $\theta^{g}$ and $\theta^{c}$ suggest that the stock of habits for both public and private consumption depreciates slowly.

The monetary policy parameters are estimated to indicate high degree of interest rate smoothing and a significant response to inflation, satisfying the Taylor principle. Since monetary policy is active for the sample considered here, fiscal rule parameters are such that government debt is fully backed by future taxes in order for the equilibrium to be determinate, and so that the intertemporal government budget constraint is satisfied. The tax rates are persistent, and have a significant response to both the level of debt and output. Capital tax rates are found to be more responsive to the state of the economy than labor tax rates. While there is evidence for automatic stabilizers for transfers, government spending is does not have a particularly large countercyclical component.

A discussion on the overall goodness of fit of the estimated model can be found in the Appendix. Figure 13 displays the actual observable series used in the estimation along with the posterior mean of their smooth version according to the estimated model. The fit for almost all variables is close to perfect. Figure 14 and Table 7 compare a set of statistics implied by the model to those measured in the data, and show that overall, the model seems to provide a good fit to the data.

\subsection{Transmission of fiscal shocks}

Figures 1- 4 show the impulse response functions as a result of shocks to the fiscal variables. The $x$-axis shows quarters after the shock hits the economy and the $y$-axis shows percentage deviations from the steady state. The impulse response functions are computed for randomly chosen 1000 parameter draws from the Monte Carlo chains. The solid lines denote the median response and the dashed lines correspond to the 5 th and $95 \mathrm{~h}$ percentiles.

Figure 1 shows that in response to a 1 percent increase in government spending, output, consumption, hours and wages rise, whereas investment falls with a delay. There are standard negative wealth effects that leads households to increase labor supply which leads to a rise in output. There is a negative wealth effect on consumption as well, but since the model embeds deep habits in public and private consumption, an increase in government spending demand induces a decline in the mark-ups. Recall, that due to deep habits when faced by a higher demand in the form of increased government spending, firms have an incentive to lower markups in order to hook a

\footnotetext{
${ }^{21}$ The parameter estimates for the preference and capacity utilization parameters are similar to the prior, but robustness of these results were verified by estimating the model with different priors, but the posterior converges to very similar values.
} 
Figure 1: Impulse response functions to a one percent increase in government spending.
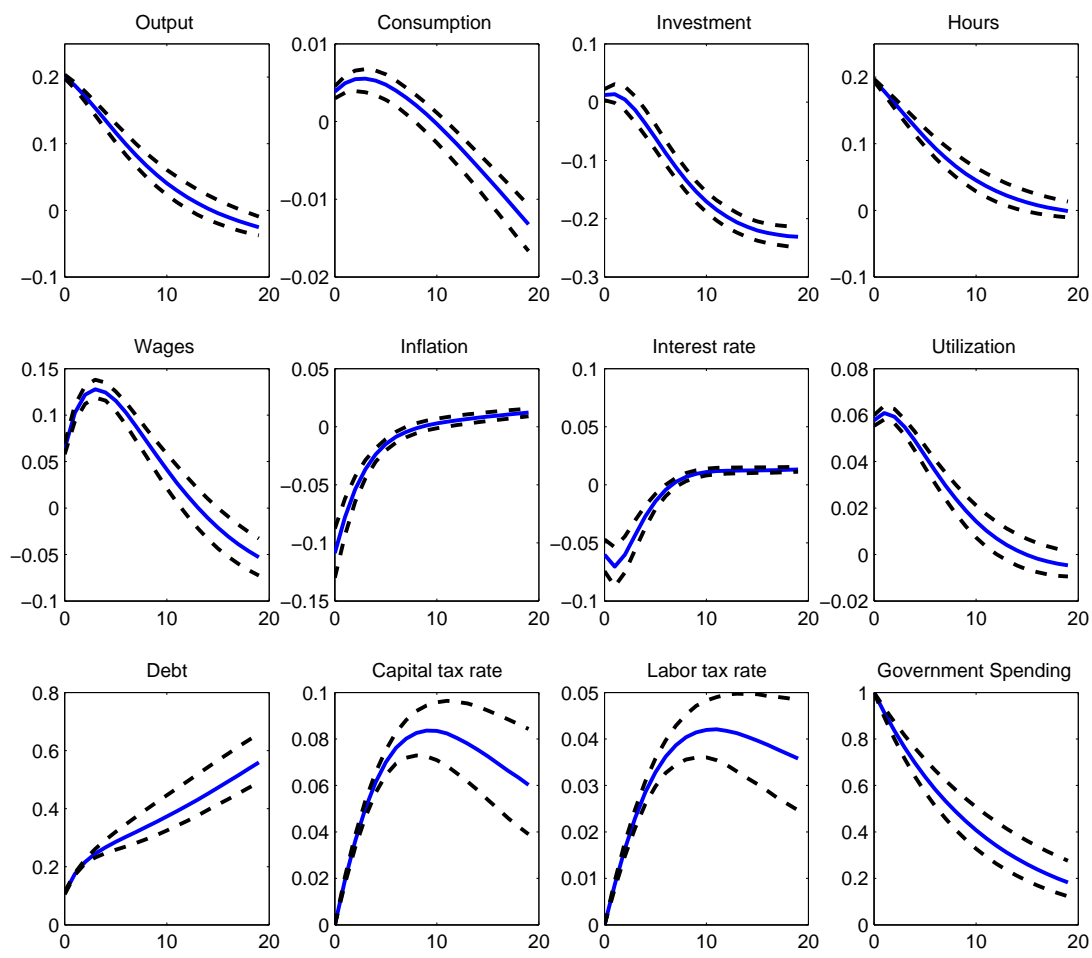

Note: The dashed lines are the $95 \%$ confidence bands. The y-axis gives the percentage deviation from steady state and the $\mathrm{x}$-axis gives the time horizon in quarters. The responses of inflation and nominal interest rate to the shock are annualized.

larger customer base in order to carry it into the next period. These variations in the markup shift the labor demand and therefore, wages increase with output as a result of an increase in demand. This higher real wage cause individuals to substitute away from leisure to consumption, and this substitution effect is large enough to offset the negative wealth effect so that overall consumption rises in response to a government spending shock. However, these effects are short-lived since the government spending is financed by a rise in distortionary taxes, which affects the marginal return on labor and capital. Investment does not move much on impact and slowly falls in response to a shock, primarily due to the rise in capital taxes. The fall in markup of prices over marginal cost is also the reason for a fall in inflation on impact, coming back slowly towards steady state as the effects of the persistent movements in markups die down. Note, however that the movements in inflation and nominal interest rate are rather small. ${ }^{22}$ Also, initially real interest rate rises in response to a government spending shock since nominal interest rate has a significant response to

\footnotetext{
${ }^{22}$ While this fall in inflation in response to a government spending shock might seem counter-intuitive it has been seen in VAR studies as well, for instance Perotti (2002) and Mountford and Uhlig (2002) who show a fall or an insignificant response of inflation to government spending shocks.
} 
Figure 2: Impulse response functions to a one percent decrease in the labor tax rate.
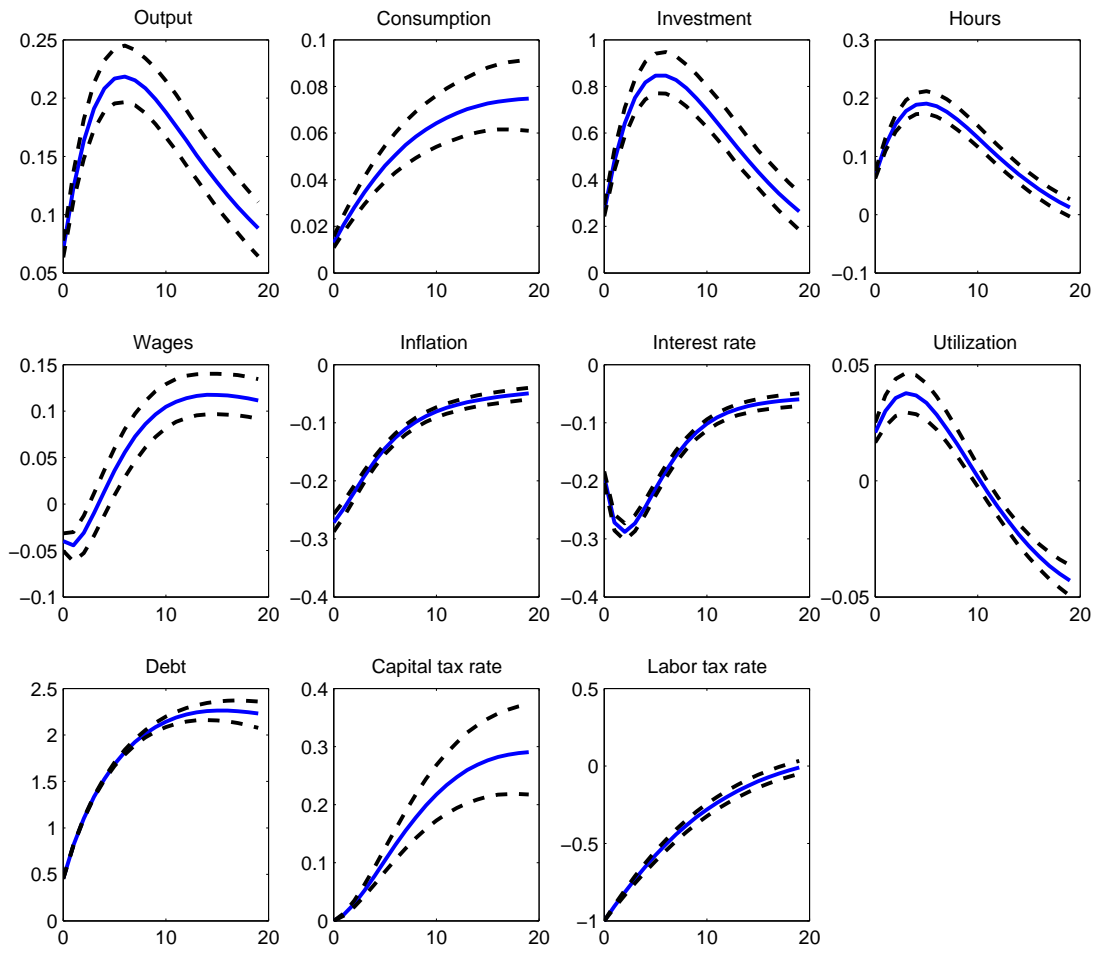

Note: The dashed lines are the $95 \%$ confidence bands. The y-axis gives the percentage deviation from steady state and the $\mathrm{x}$-axis gives the time horizon in quarters. The responses of inflation and nominal interest rate to the shock are annualized.

inflation and output deviations, but the intertemporal substitution effects which have a negative impact on consumption are too small and overall consumption rises in response to a spending shock.

The estimation is carried out using a full-information approach and fit the model to all the variation in the data, not just the dynamic effects of a spending shock. Even then, the responses of the variables are well in line with the literature on structurally identified VARs that study the effects of government spending shocks (see for example Blanchard and Perotti (2002) and Fatas and Mihov (2001)). In particular, the model is in agreement with this literature in predicting positive responses of consumption and wages to a spending shock. The positive response of consumption, however, is small in magnitude and as mentioned earlier, relatively short-lived in the model. As far as investment is concerned, Blanchard and Perotti (2002) also find an insignificant response on impact and a significantly negative response with a delay. The model predictions on investment are although different from Fatas and Mihov (2001), who show that investment falls on impact and then slowly rises to become positive. Unlike the observable used in the estimation in this paper, their measure of investment does not account for durable consumption. But they also show 
Figure 3: Impulse response functions to a one percent decrease in the capital tax rate.
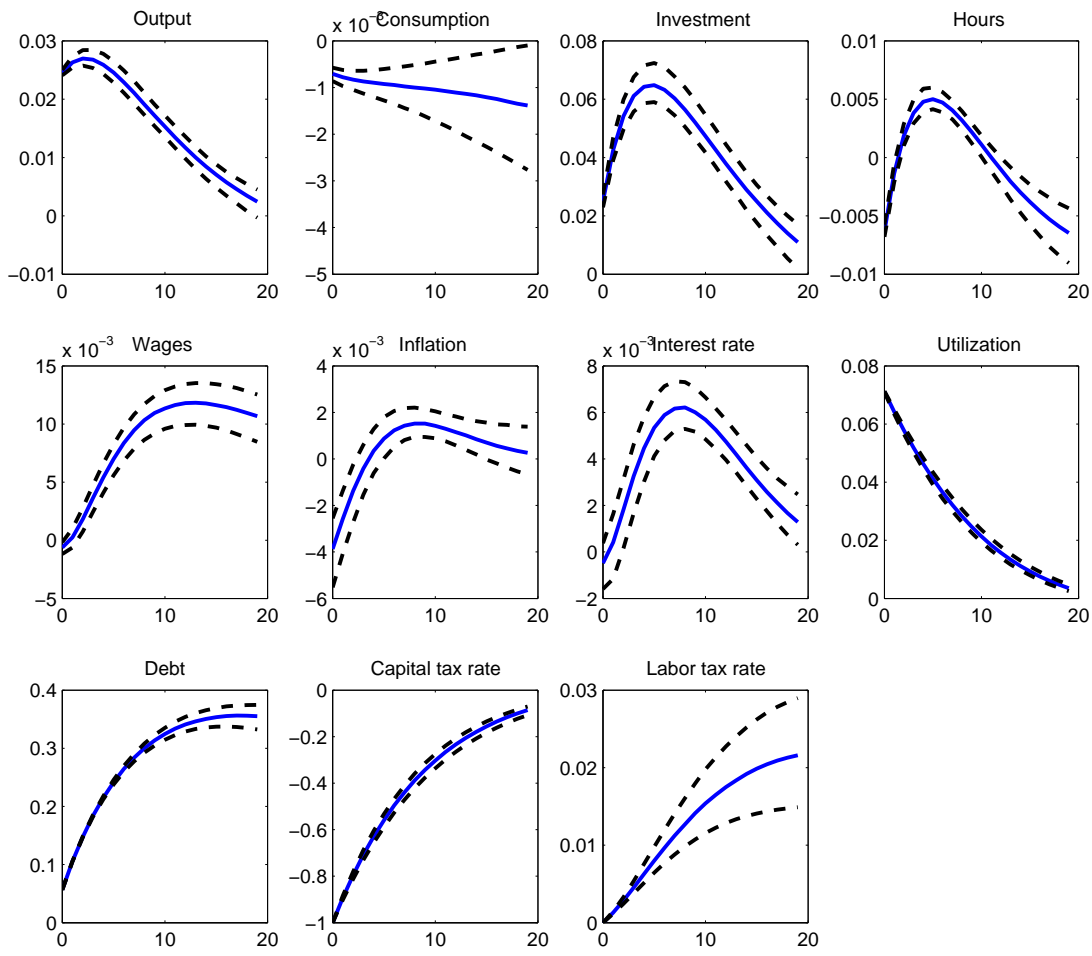

Note: The dashed lines are the $95 \%$ confidence bands. The y-axis gives the percentage deviation from steady state and the $\mathrm{x}$-axis gives the time horizon in quarters. The responses of inflation and nominal interest rate to the shock are annualized.

separately that durable consumption rises in response to a spending shock.

Figure 2 shows that in response to a 1 percent decrease in the labor tax rate, output, hours, consumption and investment all rise. Wages fall on impact and then slowly rise above steady state. There is a wealth effect that results in consumption rising and labor falling, along with an intratemporal substitution effect leading to consumption rising further and labor rising due to a higher return on labor. This rise in labor supply results in wages rising in equilibrium. The cut in labor tax rate also causes the return on capital to go up due to its effects on labor supply, leading to a rise in investment. Investment has a hump-shaped response due to investment adjustment costs. Also, note that since the degree of deep habit formation in private consumption is estimated to be high, it suggests households have a strong desire to smooth consumption, which also translates in a shift of demand from consumption to investment goods.

Figure 3 shows that a 1 percent fall in the capital tax rate results in hours, investment and wages rising. Hours rise after a slight delay and consumption has a small negative response. With a fall in capital tax rate, the after-tax return on capital goes up, resulting in a rise in investment. Here 
Figure 4: Impulse response functions to a one percent increase in transfers.
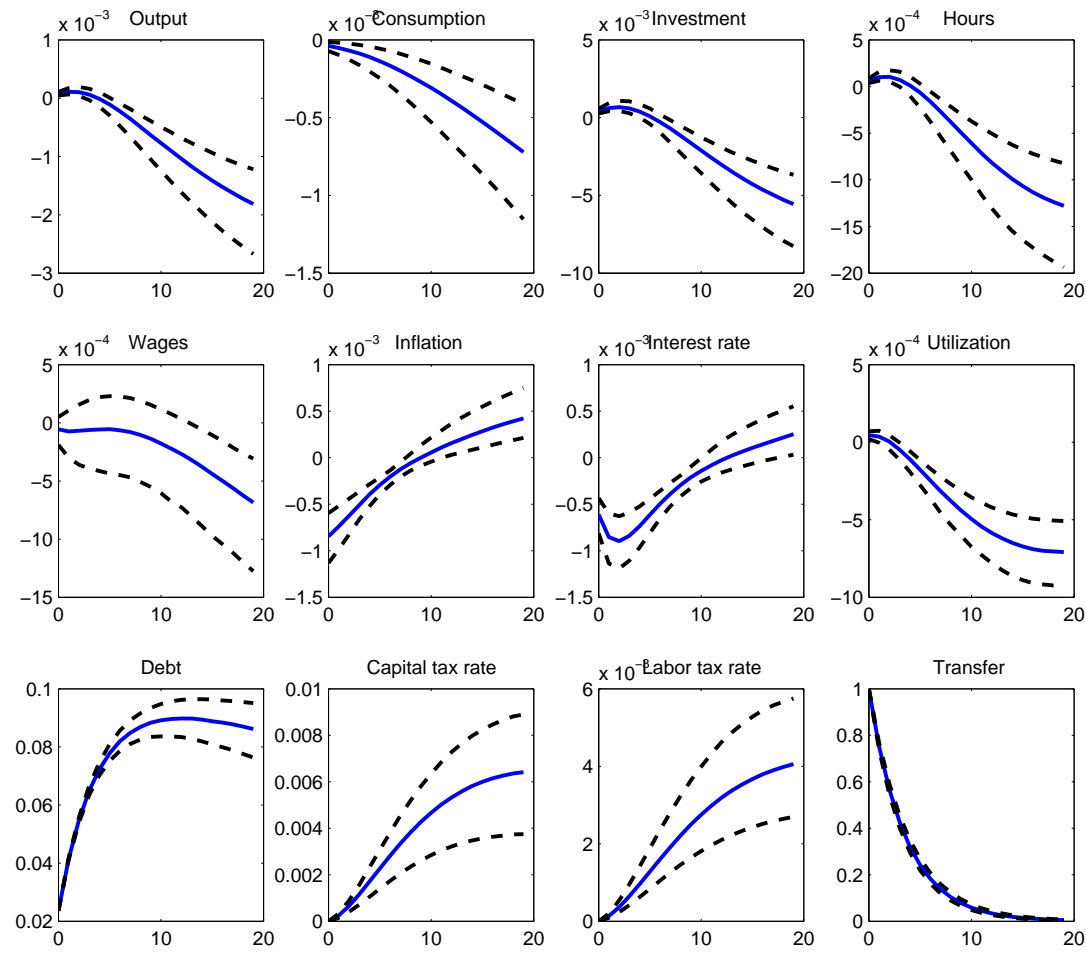

Note: The dashed lines are the $95 \%$ confidence bands. The y-axis gives the percentage deviation from steady state and the $\mathrm{x}$-axis gives the time horizon in quarters. The responses of inflation and nominal interest rate to the shock are annualized.

the response of investment is once again hump-shaped, and peaking at close to 5 quarters after the shock hits the economy, because of investment adjustment cost. Intertemporal substitution effects lead agents to delay consumption and raise labor supply. However, wealth effects work in the opposite direction. In addition, capacity utilization goes up as there is reallocation from labor to capital. These effects are generally similar to ones seen in standard neoclassical models (for example Braun (1994)). Looking at the equilibrium effects on consumption and labor, one has to take into account that soon after a fall in the capital tax rate, the labor tax rate rises to finance the deficit, and thus the consumption response is muted.

In both cases of a fall in labor and capital taxes, the model predicts a significant rise in investment. While the literature does not tend to distinguish between capital and labor taxes, Blanchard and Perotti (2002), who identify a shock to total tax revenues in a SVAR, and Romer and Romer (2007) who identify tax shocks using a narrative approach, both also find significant crowding out of investment in response to a positive tax shock. Mertens and Ravn (2008) use the narrative approach of Romer and Romer (2007) to distinguish between anticipated and unanticipated tax 
Table 3: Impact Multipliers

\begin{tabular}{|c|c|c|c|c|}
\hline \multicolumn{5}{|c|}{ Government Spending Multiplier } \\
\hline & Quarter 1 & Quarter 4 & Quarter 12 & Quarter 20 \\
\hline$\frac{\Delta Y_{t+k}}{\Delta G_{t}}$ & $\begin{array}{c}1.12 \\
{[1.10,1.13]}\end{array}$ & $\begin{array}{c}0.85 \\
{[0.79,0.90]}\end{array}$ & $\begin{array}{c}0.16 \\
{[0.06,0.26]}\end{array}$ & $\begin{array}{c}-0.14 \\
{[-0.21,-0.07]}\end{array}$ \\
\hline \multicolumn{5}{|c|}{ Labor Tax Multiplier } \\
\hline & Quarter 1 & Quarter 4 & Quarter 12 & Quarter 20 \\
\hline$\frac{\Delta Y_{t+k}}{\Delta T_{t}^{w}}$ & $\begin{array}{c}0.13 \\
{[0.11,0.15]}\end{array}$ & $\begin{array}{c}0.34 \\
{[0.32,0.41]}\end{array}$ & $\begin{array}{c}0.34 \\
{[0.28,0.40]}\end{array}$ & $\begin{array}{c}0.17 \\
{[0.11,0.22]}\end{array}$ \\
\hline \multicolumn{5}{|c|}{ Capital Tax Multiplier } \\
\hline & Quarter 1 & Quarter 4 & Quarter 12 & Quarter 20 \\
\hline$\frac{\Delta Y_{t+k}}{\Delta T_{t}^{k}}$ & $\begin{array}{c}0.33 \\
{[0.32,0.34]}\end{array}$ & $\begin{array}{c}0.36 \\
{[0.34,0.39]}\end{array}$ & $\begin{array}{c}0.19 \\
{[0.16,0.22]}\end{array}$ & $\begin{array}{c}0.04 \\
{[0.01,0.07]}\end{array}$ \\
\hline
\end{tabular}

Note: These measure the increase in the level of output $k$ quarters ahead in response to a change in the fiscal variable of interest at time $t$. The reported numbers are the median multipliers and the 95 percentiles are given below in brackets.

shocks. The responses in the model are consistent with their findings regarding responses to unanticipated tax shocks. The only exception is the response of consumption to a capital tax shock, but unlike the case shown in this paper, Mertens and Ravn (2008) consider the effects of capital tax shocks while restricting the reaction of labor taxes.

Lastly, Figure 4 shows that the responses to a 1 percent rise in lump-sum transfers are all insignificant on impact. Transfers have a positive wealth effect, but as is clear from the figure, there is a negligible effect on impact and the medium to longer run responses are driven by the rise in capital and labor taxes used to finance this increase in transfers. Therefore, there is not a significant positive stimulative effect on output.

\section{The Estimated Size of Fiscal Multipliers}

The stimulative effects of a fiscal action are generally framed in terms of multipliers. Most of the pre-existing evidence on multipliers comes from the empirical literature, which has explored different identification schemes for fiscal shocks. This paper, however, is novel in its approach of estimating both government spending and tax multipliers in the context of a structural general equilibrium model, using a full information econometric methodology.

The effects of fiscal policy are typically summarized by the impact multiplier, which is the increase in the level of output $k$ periods ahead in response to a change in the fiscal variable of 
interest given by $\Delta F_{t}$ at time $t .^{23}$

$$
\text { Impact multiplier } k \text { periods ahead }=\frac{\Delta Y_{t+k}}{\Delta F_{t}} .
$$

So the spending impact multiplier is given by, $\frac{\Delta Y_{t+k}}{\Delta G_{t}}$, and for the tax rates the impact multiplier is given in terms of the change in total tax revenues, so its $\frac{\Delta Y_{t+k}}{\Delta T_{t}}$, where $T_{t}$ denotes tax revenues. The two tax shocks are normalized so that they result in a 1 percent decrease in total tax revenues.

The impact multipliers for the estimated model are reported in Table 3, along with 95 percentile confidence bands for horizons of 1, 4, 12 and 20 quarters after the shock hits the economy. The government spending multiplier for output is 1.12 on impact and slowly decreases to be negative in the long-run. This means that on impact, a 1 percent of GDP increase in government spending results in a larger than 1 percent overall increase in GDP.

The tax multipliers in the first quarter are small. A 1 percent of GDP fall in total tax revenues driven by labor tax cuts and capital tax cuts result in a 0.13 percent and 0.33 percent rise in GDP, respectively. But the effects of taxes take time to build, and both the capital and labor tax multipliers are maximized between 4 and 12 quarters. However, magnitude-wise taxes consistently have a smaller multiplier than spending for shorter horizons, and exceed the spending multiplier for horizons of 12 and 20 quarters.

The impact multipliers, however, do not take into account that a shock at time $t$ to tax rates or government spending results in a particular future path for the fiscal instruments given by the processes defined in the modeling section. In order to capture the cumulative effects of the fiscal shock along the entire path up to a given period, I follow Mountford and Uhlig (2002), and report the present value multiplier, which also discounts future effects.

$$
\text { Present value multiplier } k \text { periods ahead }=\frac{E_{t} \sum_{j=0}^{k}(1+R)^{-j} \Delta Y_{t+j}}{E_{t} \sum_{j=0}^{k}(1+R)^{-j} \Delta F_{t+j}},
$$

gives the increase in present value of output over the next $k$ periods, as a result of a shock at time $t$ to the fiscal variable of interest, $F$.

The present value multipliers are given in Table 4. The impact and present value multipliers take the same value in quarter 1 , by definition. The present value tax multipliers build over time, whereas the spending multiplier decreases across the horizon. At longer horizons, tax and spending multipliers for output have the same magnitude. In fact, after close to 5 years, a cumulative one dollar decrease in tax revenues driven by labor tax cuts results in a one dollar increase in GDP, and exceeds the stimulative effects of increased spending. Notice also, that in terms of multipliers, labor tax cuts while not as effective as capital tax cuts in the short-run, boost output to a larger degree in the long-run.

Table 5 shows the present value spending and tax multipliers for components of GDP, consump-

\footnotetext{
${ }^{23}$ For instance the government spending multiplier is computed as follows, $\frac{\Delta Y_{t+k}}{\Delta G_{t}}=\frac{\% \Delta Y_{t+k}}{\% \Delta G_{t}} \frac{Y}{G}$, where $Y$ and $G$ are the steady state values of output and government spending respectively.
} 
Table 4: Present Value Multipliers

\begin{tabular}{|c|c|c|c|c|}
\hline \multicolumn{5}{|c|}{ Government Spending Multiplier } \\
\hline & Quarter 1 & Quarter 4 & Quarter 12 & Quarter 20 \\
\hline \multirow{2}{*}{$\frac{P V \Delta Y_{t+k}}{P V \Delta G_{t+k}}$} & 1.12 & 1.13 & 0.97 & 0.77 \\
\hline & {$[1.10,1.13]$} & {$[1.11,1.14]$} & {$[0.95,0.99]$} & {$[0.72,0.81]$} \\
\hline \multicolumn{5}{|c|}{ Labor Tax Multiplier } \\
\hline & Quarter 1 & Quarter 4 & Quarter 12 & Quarter 20 \\
\hline \multirow{2}{*}{$\frac{P V \Delta Y_{t+k}}{P V \Delta T_{t+k}^{w}}$} & 0.13 & 0.31 & 0.70 & 0.99 \\
\hline & {$[0.11,0.15]$} & {$[0.27,0.35]$} & {$[0.59,0.82]$} & {$[0.79,1.23]$} \\
\hline \multicolumn{5}{|c|}{ Capital Tax Multiplier } \\
\hline & Quarter 1 & Quarter 4 & Quarter 12 & Quarter 20 \\
\hline \multirow{2}{*}{$\frac{P V \Delta Y_{t+k}}{P V \Delta T_{t+k}^{k}}$} & 0.33 & 0.44 & 0.64 & 0.76 \\
\hline & {$[0.32,0.34]$} & {$[0.42,0.46]$} & {$[0.58,0.71]$} & {$[0.64,0.90]$} \\
\hline
\end{tabular}

Note: These measure the present discounted value of the cumulative change in output over the present value cumulative change in the fiscal variable of interest, over the $k$ quarters. The reported numbers are the median multipliers and the 95 percentiles are given below in brackets.

tion and investment. The spending multiplier for consumption is found to be positive, however rather small in the short-run, and in the long-run is negative. This positive multiplier for consumption is in line with structural VAR studies, while in contrast to standard models that do not explicitly introduce a mechanism for public spending shock to transmit through the economy. The spending multiplier for investment is not significant in the first few quarters but becomes negative in the long-run. The positive multiplier for consumption and the insignificant response of investment on impact also explain the size of the spending multiplier for output, being larger than one. If for instance, consumption and investment are both crowded out in response to a spending shock, and have negative multipliers, then the resulting multiplier for output would be less than one. ${ }^{24}$

Consumption has a small and positive multiplier in response to a labor tax shock on impact which becomes larger at longer horizons. Conversely, the consumption multiplier is small and negative in response to a capital tax shock. Also, notice that the multiplier for investment in response to both tax shocks is sizable. This suggests that the expansionary effects of both labor and capital tax cuts on output are primarily driven by the stimulative effects on investment.

Table 5 also shows the multipliers for hours worked in the model, since the main motivation behind a fiscal stimulus plan is typically to boost demand and to raise employment. ${ }^{25}$ Employment

\footnotetext{
${ }^{24}$ This is true in the estimated DSGE model of Smets and Wouters (2007), which is not developed to study fiscal policy, as they do not consider a transmission mechanism for government spending shocks and assume spending financed by lump-sum taxes.

${ }^{25}$ It might be worthwhile, however, to consider a model with search frictions in the labor market, to fully explain the effects of fiscal shocks on labor, both at the extensive (employment) and intensive (hours per worker) margins.
} 
Table 5: Present Value Multipliers for Consumption, Investment and Hours

\begin{tabular}{|c|c|c|c|c|}
\hline \multicolumn{5}{|c|}{ Government Spending Multiplier } \\
\hline & Quarter 1 & Quarter 4 & Quarter 12 & Quarter 20 \\
\hline \multirow{2}{*}{$\frac{P V \Delta C_{t+k}}{P V \Delta G_{t+k}}$} & 0.013 & 0.019 & 0.018 & -0.004 \\
\hline & {$[0.010,0.015]$} & {$[0.014,0.022]$} & {$[0.009,0.022]$} & {$[-0.021,0.005]$} \\
\hline \multirow{2}{*}{$\frac{P V \Delta I_{t+k}}{P V \Delta G_{t+k}}$} & 0.017 & 0.013 & -0.113 & -0.268 \\
\hline & {$[0.006,0.028]$} & {$[-0.009,0.036]$} & {$[-0.164,-0.070]$} & {$[-0.356,-0.193]$} \\
\hline \multirow{4}{*}{$\frac{P V \Delta H_{t+k}}{P V \Delta G_{t+k}}$} & 0.670 & 0.661 & 0.582 & 0.507 \\
\hline & {$[0.663,0.677]$} & {$[0.658,0.667]$} & {$[0.567,0.593]$} & {$[0.479,0.525]$} \\
\hline & \multicolumn{3}{|c|}{ Labor Tax Multiplier } & \\
\hline & Quarter 1 & Quarter 4 & Quarter 12 & Quarter 20 \\
\hline \multirow{2}{*}{$\frac{P V \Delta C_{t+k}}{P V \Delta T_{t+k}^{w}}$} & 0.015 & 0.034 & 0.105 & 0.205 \\
\hline & {$[0.013,0.019]$} & {$[0.028,0.042]$} & {$[0.085,0.129]$} & {$[0.158,0.263]$} \\
\hline \multirow{2}{*}{$\frac{P V \Delta I_{t+k}}{P V \Delta T_{t+k}^{w}}$} & 0.105 & 0.255 & 0.569 & 0.778 \\
\hline & {$[0.095,0.118]$} & {$[0.230,0.281]$} & {$[0.497,0.656]$} & {$[0.641,0.950]$} \\
\hline \multirow{2}{*}{$\frac{P V \Delta H_{t+k}}{P V \Delta T_{t+k}^{w}}$} & 0.081 & 0.187 & 0.371 & 0.450 \\
\hline & {$[0.074,0.09]$} & {$[0.171,0.209]$} & {$[0.324,0.434]$} & {$[0.369,0.560]$} \\
\hline
\end{tabular}

Capital Tax Multiplier

\begin{tabular}{ccccc}
\hline & Quarter 1 & Quarter 4 & Quarter 12 & Quarter 20 \\
\hline$\frac{P V \Delta C_{t+k}}{P V \Delta T_{t+k}^{k}}$ & -0.006 & -0.009 & -0.018 & -0.031 \\
& {$[-0.008,-0.005]$} & {$[-0.010,-0.007]$} & {$[-0.024,-0.011]$} & {$[-0.047,-0.014]$} \\
$\frac{P V \Delta I_{t+k}}{P V \Delta T_{t+k}^{k}}$ & 0.072 & 0.163 & 0.326 & 0.419 \\
& {$[0.066,0.079]$} & {$[0.147,0.182]$} & {$[0.282,0.380]$} & {$[0.336,0.514]$} \\
$\frac{P V \Delta H_{t+k}}{P V \Delta T_{t+k}^{k}}$ & -0.053 & -0.006 & 0.032 & -0.005 \\
& {$[-0.049,-0.057]$} & {$[-0.014,0.002]$} & {$[0.017,0.047]$} & {$[-0.037,0.024]$}
\end{tabular}

Note: The reported numbers are the median multipliers and the 95 percentiles are given below in brackets. 
has a significantly positive spending multiplier, which is largest on impact, and slowly decaying over the horizon. This increase in hours worked, as a result of increased public spending, is due to both a rise in labor supply and demand. Labor supply shifts mainly because of households anticipating an increase in taxes, and price rigidities and countercyclical markups lead to a rise in labor demand of the firms with the shift in aggregate demand. The employment multiplier is also positive for labor tax cuts, and while on impact the effects are small, they build significantly over time. These effects are primarily driven by the increase in labor supply due to the resulting higher return on labor. Unlike increased spending and labor tax cuts, capital tax cuts do not stimulate hours worked on impact. The multiplier for hours worked is positive for a range of 5-18 quarters after the shock hits the economy, but even then the magnitude is much smaller than the effects of alternative fiscal instruments. This suggests that increased government spending and lowering labor taxes are effective at stimulating hours worked.

There are some recent DSGE models where the effects of a spending shocks are estimated and spending multipliers can be inferred. (See for example Coenen and Straub (2005), Lopez-Salido and Rabanal (2006) and Forni, Monteforte, and Sessa (2009).) These papers consider mechanisms to replicate the positive response of consumption to a spending shock, as suggested by VAR evidence, and find the spending multiplier in the range of 0.7 and 2. On the other hand, there has been no significant prior work done on estimating tax multipliers in a structural model. ${ }^{26}$

There is, however, a great deal of evidence in the VAR literature measuring the stimulative effects of spending increases and tax cuts. Studies employing structural VARs, such as Fatas and Mihov (2001), Blanchard and Perotti (2002) and Gali, Lopez-Salido, and Valles (2007), also find output multipliers for spending close to $1 .^{27}$ As mentioned earlier, these papers also find positive consumption multipliers. Blanchard and Perotti (2002) also emphasize the negative effect on investment of an increase in government purchases, which is seen in the model at longer horizons of 12 and 20 quarters.

The slow rise in the stimulative effects of tax cuts are also documented in this literature, for example by Blanchard and Perotti (2002), Romer and Romer (2007) and Mountford and Uhlig (2002). The effects of tax shocks found here, however, are smaller than the ones documented in these studies. One of the reasons is that they consider a shock to total tax revenues and do not distinguish between labor and capital taxes. Mountford and Uhlig (2002) also document large effects of tax cuts because they consider deficit financed tax shocks, whereas in the model, once labor taxes are lowered in order to stimulate the economy, there is an eventual increase in capital taxes in response to the resulting deficit. The significant response of investment to the tax shocks is also found in this literature. Both Romer and Romer (2007) and Blanchard and Perotti (2002), though employing different identification schemes, find that tax raises are highly contractionary

\footnotetext{
${ }^{26}$ An exception is Forni, Monteforte, and Sessa (2009) who estimate both tax and spending multipliers for the Euro area.

${ }^{27}$ Ramey (2008) employs a narrative approach, based on identifying episodes of large military buildups, and finds the maximum spending multiplier to be 1.1. Mountford and Uhlig (2002) use a sign restrictions approach to identify fiscal shocks, and find the spending multiplier to be 0.65 . These variations in the multipliers can be attributed to differences in identification schemes.
} 
primarily due to the effects on investment.

\section{Counterfactual Fiscal Policy Experiments}

\subsection{Deficits versus Tax Financing}

In the baseline model, government spending is financed by an increase in taxes and government debt. In this section, I evaluate the scenario where the government, relative to the historically estimated rules, is more or less aggressively committed to retiring the debt. This is done in a similar manner to the exercise shown in Uhlig (2009), where the rate at which taxes respond to the level of debt is varied. More precisely, the processes for labor and capital tax rates are given as follows,

$$
\begin{gathered}
\hat{\tau}_{t}^{k}=\rho_{k} \hat{\tau}_{t-1}^{k}+\gamma \rho_{k, b} \hat{b}_{t-1}+\rho_{k, y} \hat{y}_{t-1}+\epsilon_{t}^{k}, \\
\hat{\tau}_{t}^{w}=\rho_{w} \hat{\tau}_{t-1}^{w}+\gamma \rho_{w, b} \hat{b}_{t-1}+\rho_{w, y} \hat{y}_{t-1}+\epsilon_{t}^{w},
\end{gathered}
$$

where $\gamma=1$ corresponds to the baseline estimated rule. When $\gamma$ is less than 1 , then taxes are less responsive to debt and government spending is primarily financed by issuing debt. The values of $\gamma>1$ correspond with taxes rising more aggressively in response to a deficit, and so government spending is financed by higher taxes than the baseline case.

Figure 5 shows the present value spending multiplier for output at various horizons, as $\gamma$ is varied between 0.5 and 10 , where 0.5 is the smallest value for which the equilibrium is determinate. In the short-run both the spending and output multipliers are generally unaffected as taxes are overall slow to adjust to the rising level of debt. However, at longer horizons the multipliers become significantly smaller when taxes respond more aggressively to the level of debt, in response to spending and tax shocks. In the case of tax shocks, because agents in the economy internalize that a tax cut today will be financed by aggressive tax increases in the future, the present value multipliers for longer horizons in fact become negative.

Figure 6 shows the evolution of debt over a horizon of 20 quarters for varying degrees of $\gamma$, in response to a government spending shock. Typically, debt takes as long as 50-100 years to come back to steady state. The slow evolution of debt has been documented by others, such as Chung and Leeper (2007). After fiscal disturbances hit the economy, when $\gamma$ is as high as 5 or 10, then debt returns to steady state in 5-15 years. In conclusion, while the multipliers are mostly unaffected at shorter horizons of up to a year, the method of financing, either by increased deficits or raising taxes, is important for longer-run consequences.

\subsection{Lump-sum versus Distortionary Taxation}

A common assumption in the literature is exogenous fiscal policy with deficits financed by lumpsum taxes, which implies Ricardian equivalence holds and the timing of the taxes does not affect the equilibrium. However, as pointed out in Baxter and King (1993), in a neoclassical model there are significant differences between government spending financed by changes in tax rates or changes in 
Figure 5: Counterfactual experiment: Deficit versus tax financing
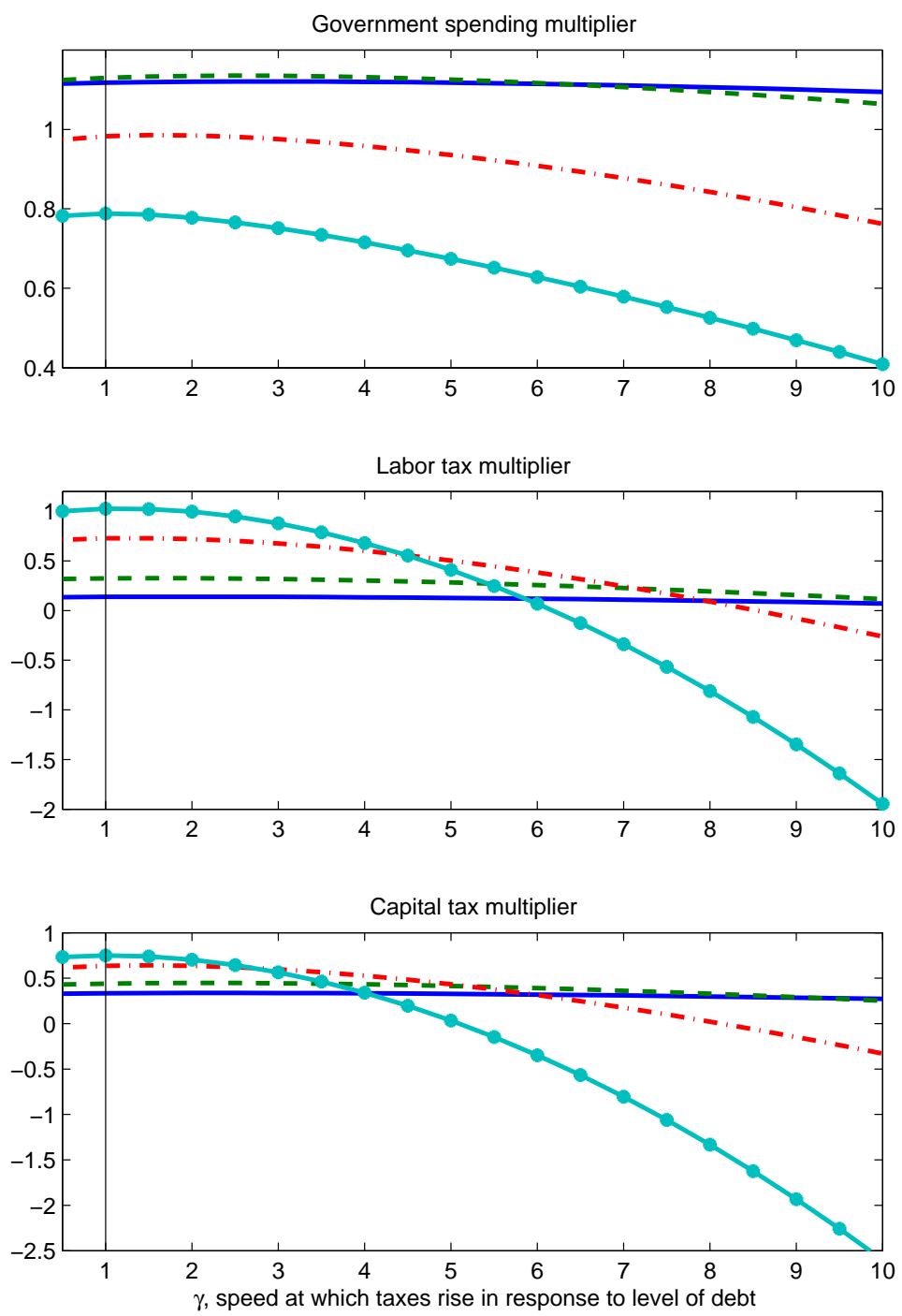

1st qtr $-=-4$ th qtr,,,-- 12 th qtr $\longrightarrow-20$ th qtr

Note: The $\mathrm{x}$-axis is the value of $\gamma$, the speed at which taxes respond to debt in the counterfactual exercise. $\gamma=1$ corresponds to the baseline estimated model. 
Figure 6: Response of debt to a government spending shock for varying values of $\gamma$

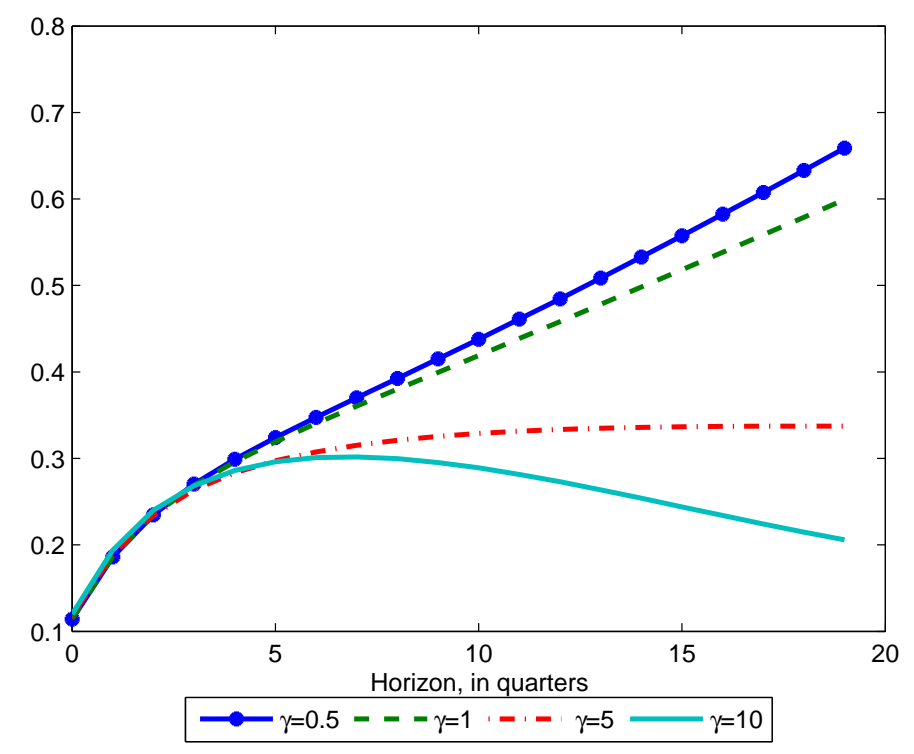

Note: $\gamma$ is the speed at which taxes respond to debt in the counterfactual exercise. $\gamma=1$ corresponds to the baseline estimated model. The $\mathrm{x}$-axis gives the time horizon in quarters.

lump-sum transfers. The changes in lump-sum transfer payments are equivalent to debt financing when sequences for tax rates are fixed. In fact, in their calibrated model, there is a negative effect on output of an increase in government purchases when it is financed entirely by distortionary taxes. This is because of strong substitution effects on labor supply of tax rates.

In this section, the spending multiplier in the case of the estimated endogenous rules for tax rates are compared with the scenario when instead of the distortionary taxes responding, the spending is financed by lump-sum taxes. This is done by shutting down the response of the distortionary taxes, by setting $\hat{\tau}_{t}^{w}=\hat{\tau}_{t}^{k}=0$. In order to model the increase in lump-sum taxes instead, in Equation (16), I consider an additional term, where lump-sum transfers respond to the level of debt. This means that after an increase in government spending, while tax rates do not respond, lump-sum transfers adjust to ensure fiscal solvency and the return of the level of debt to steady state. ${ }^{28}$

Figure 7 shows that the present value spending multiplier for output is consistently lower in the case of spending financed by distortionary taxes. Note, however, that the method of financing government spending, at least in the short run does not have very significant effects. This is because, in the baseline model with distortionary taxes, the tax rates do not respond on impact and otherwise evolve slowly. Looking at the longer horizon, in the case of spending financed by lump-sum taxes, the multiplier is near one even close to 20 quarters, whereas in the estimated model with endogenous tax rates, the multiplier significantly decreases over time. This points

\footnotetext{
${ }^{28}$ This is done by setting the coefficient of transfer to lagged debt, $\rho_{t r, b}=-0.1$, where this values ensures determinacy of equilibrium or the intertemporal government budget constraint being satisfied.
} 
Figure 7: Counterfactual experiment: Lump-sum versus distortionary taxation

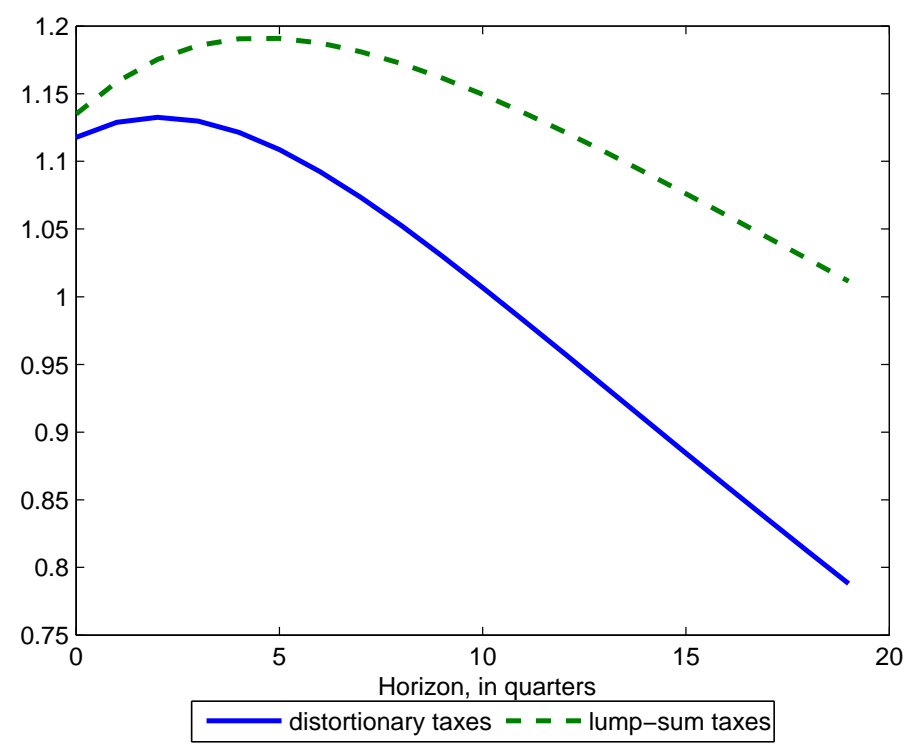

Note: The present value spending multiplier for output is computed under the estimated model with the endogenous estimated rule for tax rates and in the case when tax rates do not respond and spending is financed by lump-sum taxes instead. The x-axis gives the time horizon in quarters.

towards careful consideration of conclusions about effects of fiscal policy in simpler models where government purchases are assumed to be financed entirely by lump-sum taxes which is equivalent to deficit financing.

\subsection{Automatic Stabilizers}

In this section, the role of automatic stabilizers is explored on the present value spending multiplier for output. These capture changes in government revenues and expenditures due to the changes in the state of the economy and do not require any discretionary action on the part of the government while playing the role of stabilizing fluctuations in the economy. This is done by varying the value of $\mu$ in the following processes,

$$
\begin{gathered}
\hat{\tau}_{t}^{k}=\rho_{k} \hat{\tau}_{t-1}^{k}+\rho_{k, b} \hat{b}_{t-1}+\mu \rho_{k, y} \hat{y}_{t-1}+\epsilon_{t}^{k}, \\
\hat{\tau}_{t}^{w}=\rho_{w} \hat{\tau}_{t-1}^{w}+\rho_{w, b} \hat{b}_{t-1}+\mu \rho_{w, y} \hat{y}_{t-1}+\epsilon_{t}^{w}, \\
\hat{g}_{t}=\rho_{g} \hat{g}_{t-1}+\mu \rho_{g, y} \hat{y}_{t-1}+\epsilon_{t}^{g}, \\
\hat{t r_{t}}=\rho_{t r} \hat{t r}_{t-1}+\mu \rho_{t r, y} \hat{y}_{t-1}+\epsilon_{t}^{t r} .
\end{gathered}
$$

Figure 8 reports the present value spending multiplier at different horizons for different values of $\mu$. The automatic stabilizers take the estimated values when $\mu=1$. In the case of a government 
Figure 8: Present value government spending multiplier for output for varying values of $\mu$

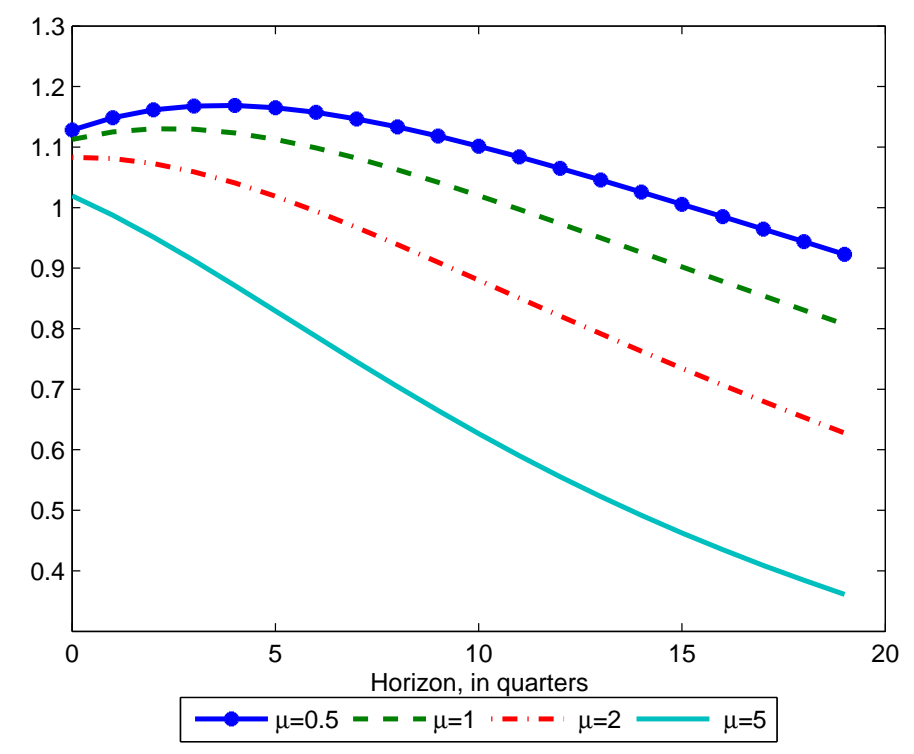

Note: $\mu$ is the speed at which automatic stabilization takes place in the counterfactual exercise. $\mu=1$ corresponds to the baseline estimated model. The x-axis gives the time horizon in quarters.

spending shock hitting the economy, it raises output, which results in a rise in capital and labor tax rates, and a decrease in transfers due to their countercyclical nature.

Now, when these stabilizers are larger, in order to dampen short-run fluctuations in the economy, the effects of an increase in government spending are reduced at all horizons, since the economy is stabilized by further increases in taxes and decreases in transfers. However, even though this is a short-run mechanism for mitigating the impact on demand, the effects in the long-run are further exacerbated, as seen in the diverging present value multipliers at horizons close to 20 quarters.

\section{Sensitivity of Fiscal Multipliers to Monetary Policy}

In this section, I consider how the stance of the monetary policy affects the size of fiscal multipliers. The role of monetary authority is important in determining the movements of the real interest rate, which through intertemporal effects plays a role in how macroeconomic variables react to fiscal shocks.

I start by exploring how the coefficients in the monetary policy rule affect the impact multiplier of output in response to the government spending, capital and labor tax shocks, shown in Figure 9. In the top panel, the nominal interest rate smoothing parameter, $\alpha_{R}$, is varied between 0.01 and 0.99, keeping the other parameters constant. The spending and capital tax multipliers for output rise with a higher value of $\alpha_{R}$, whereas the labor tax multiplier falls for higher values of the parameter. This is because in the case of spending and capital tax cuts, a higher value of 
$\alpha_{R}$ means the monetary authority increases the real interest rate less rapidly, thus increasing the expansionary effects of these fiscal actions. In response to a labor tax cut, the model predicts a fall in inflation. Therefore higher values of $\alpha_{R}$ imply that the desire to smooth interest rate strengthens in opposition to the downward pressure on interest rate due to effects of inflation.

The middle panel of Figure 9 shows that as the coefficient on inflation in the monetary policy rule, $\alpha_{\pi}$ is perturbed, it does not significantly alter the impact multipliers in the case of increased government spending or reduced taxes overall. This is because inflation has a limited response to the fiscal shocks. However, notice also that as $\alpha_{\pi}$ increases, the largest effect is on the impact labor tax multiplier, which decreases. This is because a labor tax cut causes households to increase labor supply due to a higher return on labor. This causes a fall in wages and lower marginal costs results in a fall in inflation. Therefore a larger response to inflation results in a smaller rise in real interest rate, though these effects are small in magnitude.

The last panel, shows that as the coefficient on output, $\alpha_{Y}$, is varied between 0 and 0.5 , the impact multipliers are significantly affected, particularly in the case of the government spending multiplier for output. As $\alpha_{Y}$ rises, the impact multiplier for output uniformly falls in the case of all fiscal shocks. If the nominal interest rate are highly responsive to the deviations of output from the steady state, then in the case of both spending and tax shocks, the nominal interest rate will rise sharply, causing the real interest rate to go up. This leads to a fall in aggregate demand and results in a smaller output multiplier. ${ }^{29}$

The role of monetary policy is explored further by considering two extreme cases, one where the monetary authority is very aggressive in stabilizing both inflation and output ( $\alpha_{\pi}=2$ and $\left.\alpha_{Y}=0.5\right)$, and the second where the monetary policy does not react significantly to variations in the state of the economy $\left(\alpha_{\pi}=1.1\right.$ and $\left.\alpha_{Y}=0\right) .{ }^{30}$ Figure 10 shows the present value fiscal multipliers for output, consumption and investment under these two rules and the estimated monetary policy rule. The $\mathrm{x}$-axis shows the horizon in quarters.

The first row in Figure 10 shows the present value government spending multiplier. The multipliers for all components of demand are found to be larger than the baseline case under the accommodative monetary policy, and smaller in the case of the aggressive monetary rule. In the estimated model, because markups are countercyclical, a government spending shock leads to an initial small decline in inflation, and inflation eventually rises once aggregate demand comes back to normal. The nominal interest rate responds significantly to both inflation and the rise in output, and overall this results in a rise in the real interest rate. In the case of aggressive monetary policy, the real interest rate rises more than the baseline scenario which is primarily due to the strong response to deviations in output from the steady state. This leads to a fall in both consumption and investment demand in response to a government spending shock, and the output multiplier is less than one, even on impact. The case of monetary policy with a limited response to inflation and output results in the real interest rate falling in response to a government spending shock,

\footnotetext{
${ }^{29}$ These effects of the size of the coefficient on deviations of output in the monetary policy rule, $\alpha_{Y}$, on aggregate demand in response to a government spending shock, are also pointed out in Linnemann and Schabert (2003).

${ }^{30}$ Note that $\alpha_{\pi}=1.1$ is the smallest reaction consistent with a determinate equilibrium in the estimated model.
} 
Figure 9: Sensitivity of fiscal multipliers to monetary rule parameters
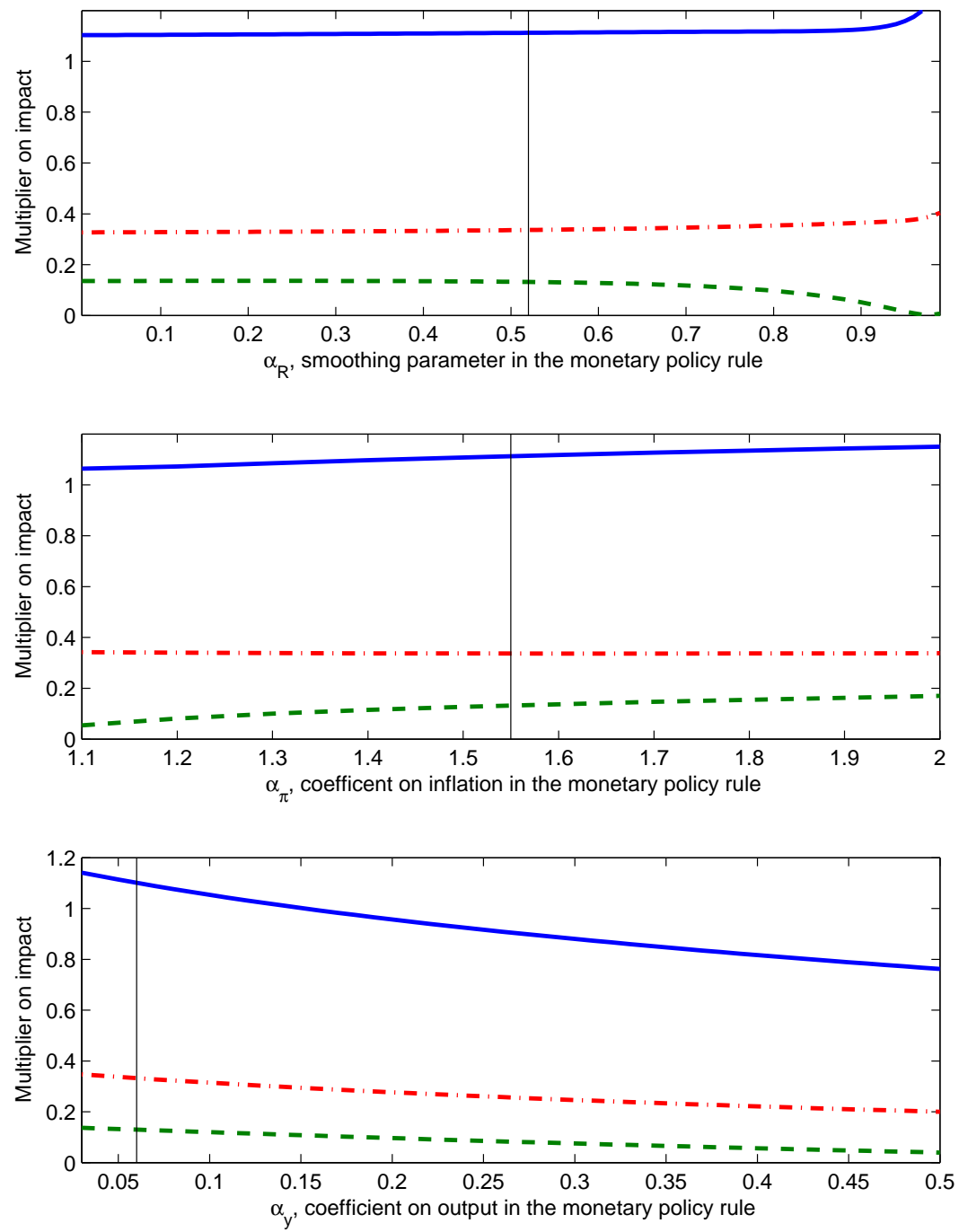

Government spending multiplier = - - Labor tax multipltier : - - - Capital tax multiplier

Note: The top panel shows the government spending, labor and capital tax multipliers on impact for output, for varying degree of $\alpha_{R}$, the smoothing parameter, the middle panel shows multipliers for varying degree of $\alpha_{\pi}$, the coefficient on inflation and the bottom panel shows the multipliers when $\alpha_{Y}$, the coefficient on output, is varied in the Taylor type monetary policy rule. The vertical lines correspond to the estimated values of the parameters. 
which creates an incentive for agents to consume and invest more, thus raising the government spending multiplier. This suggests that if the monetary authority reacts strongly to the state of the economy, then it limits the stimulative effects of increased government spending. Alternatively, in the presence of a relatively accommodative monetary policy, government spending has a higher stimulative effect on aggregate demand. ${ }^{31}$

The same effects are at play in response to a capital tax cut, as shown in the second row of Figure 10, so that an accommodative monetary policy results in a higher overall stimulative effects on output, consumption and investment.

However, less responsive monetary policy does not imply a larger stimulative effect in the case of all fiscal measures. The last row of Figure 10 shows the labor tax multiplier in the case of the estimated monetary policy rule, along with the two alternate rules. The labor tax multipliers for output, consumption and investment are lower in the case of both new rules, relative to the estimated monetary policy rule. When $\alpha_{\pi}=1.1$ and $\alpha_{Y}=0$, since inflation falls in response to the cut in labor taxes, a smaller response to inflation results in a larger rise in real interest rate than the baseline estimated model, causing components of demand to fall. This leads to a smaller multiplier effect of labor tax cuts when the monetary policy is not reacting strongly to both inflation and output. In the case of $\alpha_{\pi}=2$ and $\alpha_{Y}=0.5$, the rise is real interest rate is limited due to the large response to inflation, but because of the aggressive response to deviations of output from steady state, overall real interest rate rises much more than the baseline case. This once again results in a smaller multiplier in response to a labor tax cut.

In this section, I have shown that the stance of monetary policy has important implications for the size of fiscal multipliers. An accommodative monetary policy that has a limited response to inflation and output deviations, results in higher overall stimulative effects of increased spending and capital tax cuts. This is however, not the case for all fiscal measures, as shown in the case of labor tax cuts. In this paper, I consider the case of active monetary policy, since fiscal policy is estimated to be passive. Recent work by Cogan, Cwik, Taylor, and Wieland (2009), Christiano, Eichenbaum, and Rebelo (2009) and Eggertsson (2009) provide supporting evidence, to show that when the monetary policy is completely unresponsive or the nominal interest is at the zero bound, the monetary-fiscal interactions have significant effects on the size of fiscal multipliers.

\section{Simulating the American Recovery and Reinvestment Act of 2009}

In early 2009, the US Congress passed a $\$ 787$ billion package in order to stimulate the economy. The stimulus package comprises of both increased government spending and tax cuts. In this

\footnotetext{
${ }^{31}$ Davig and Leeper (2009) also document similar interactions between monetary policy and the size of fiscal stimulus due to increased spending, where monetary policy determines the size of the implied intertemporal substitution effects arising in response to a spending shock, and thus the ultimate response of components of aggregate demand. Their focus however is regime switching in both monetary and fiscal policy, and they characterize fiscal multipliers also in the regime where monetary policy is passive and fiscal policy is active.
} 
Figure 10: Fiscal multipliers for various monetary policy rules.
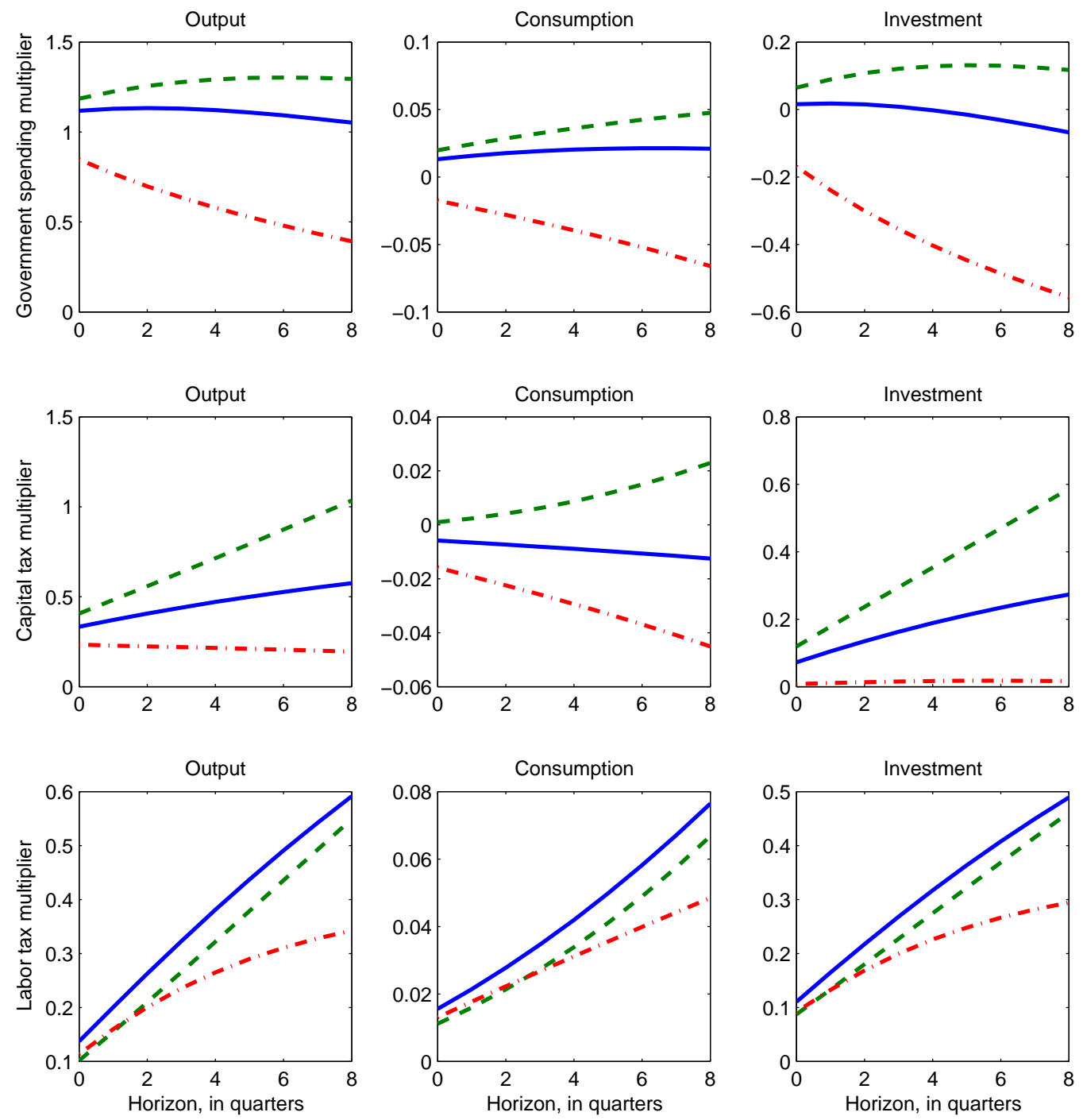

Estimated rule $---\alpha_{\pi}=1.1, \alpha_{\mathrm{Y}}=0,-\infty, \alpha_{\pi}=2, \alpha_{\mathrm{Y}}=0.5$

Note: The first row shows the present value spending multiplier for output, consumption and investment at various horizons. The second row shows the present value capital tax multipliers, and the last row shows the present value labor tax multipliers. The x-axis gives the time horizon in quarters. The solid line is the baseline estimated model, the dashed line is the passive monetary policy rule $\left(\alpha_{\pi}=1.1\right.$ and $\left.\alpha_{Y}=0\right)$ and the dash dotted line is the aggressive monetary policy rule $\left(\alpha_{\pi}=2\right.$ and $\left.\alpha_{Y}=0.5\right)$. 
Figure 11: Simulating the American Recovery and Reinvestment Act of 2009
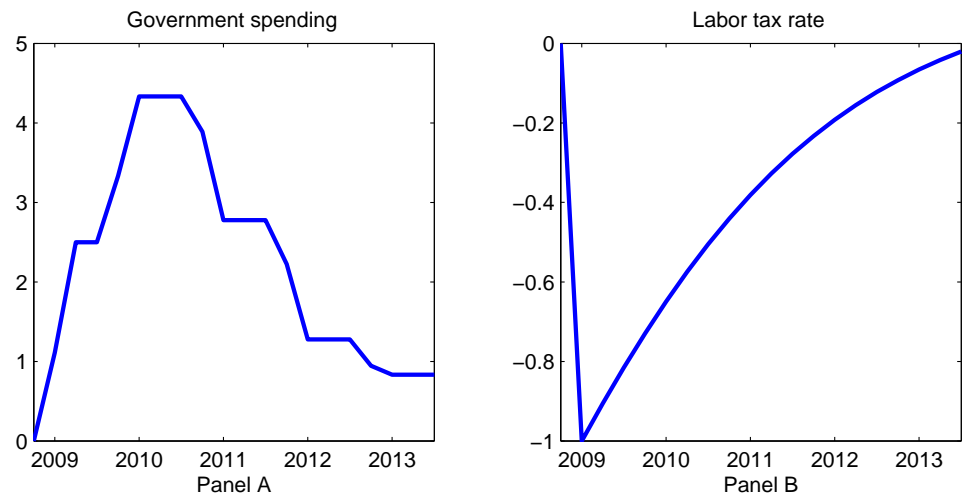

Note: Panel A shows the implied government spending path and Panel B shows the labor tax cut implied by the stimulus package. The y-axis gives percentage deviations from steady state.

section, the effects of the package on the economy are analyzed by simulating the implied changes in government spending and taxes in the estimated model.

In order to analyze the impact of increased spending contained in the stimulus package, note that two thirds of the bills goes towards public investment and government purchases, and aid to state governments. These government purchases, are mostly one time only expenditures and phased to take place over the course of several years. The transfers to state and local governments are to be used both for purchases of goods and services, and towards avoiding raising taxes. Romer and Bernstein (2009) assume that $60 \%$ of these transfers are used towards spending. Cogan, Cwik, Taylor, and Wieland (2009) use this assumption and report the path of government purchases as a share of GDP due to the stimulus package, over the course of the next few years. Roughly a third of the package goes towards tax cuts. The largest component, close to $\$ 116$ billion, is in the form of payroll tax credits. ${ }^{32}$ In the model, these payroll tax credits can be thought of as a cut in the labor income tax rate. ${ }^{33}$

In order to simulate the American Recovery and Reinvestment Act of 2009 in the model, the path of government purchases from this stimulus package, as specified by Cogan, Cwik, Taylor, and Wieland (2009), is introduced as a sequence of anticipated shocks into the economy. This means that in 2009:I, agents in the economy observe the entire path of expected government spending as shown in Figure 1, Panel A. In addition, the tax cut is introduced as a 1\% cut in labor income taxes in 2009:I, as shown in Figure 1, Panel B. Next the responses to both these shocks are computed in the model and are shown in Figure 2. The model predicts that the effects on GDP of the stimulus

\footnotetext{
${ }^{32}$ The rest are tax cuts for individuals in the form of expanded child credits, college credit, home buyer's credit etc. A small fraction are tax cuts for companies, for example to use current losses to offset profits made in the previous five years and extended tax credits for renewable energy production.

${ }^{33}$ Since, these payroll tax credits are close to 2 percent of the total tax revenues, and Blanchard and Perotti (2002) estimate the output elasticity of total tax revenues to be 2.08 , this can be thought of as a $1 \%$ decrease in the tax rate. Uhlig (2009) also simulate this tax change as a $1 \%$ reduction in the labor tax rate.
} 
Figure 12: Impact of the American Recovery and Reinvestment Act of 2009
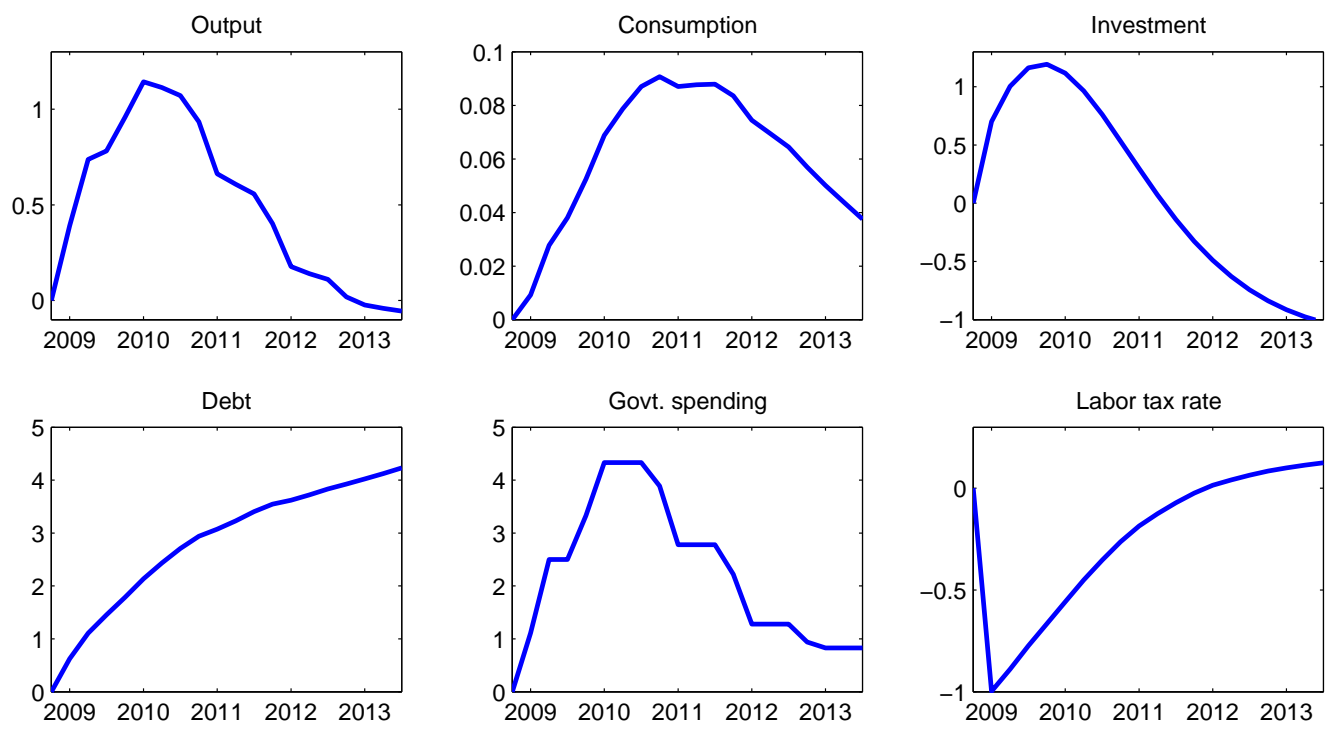

Note: Impact of combined fiscal actions, increased spending and cut in labor taxes, implied by the ARRA 2009. The y-axis gives percentage deviations from steady state.

package would be most significantly felt during early 2010. There is a small increase in output initially as the households anticipate larger spending in the following years and while the tax cuts are initialized in 2009, their effects take time to build and the largest impact on GDP is a few quarters after the initial shock. Also notice that by late 2012, output multiplier is negative, even though government spending is still above steady state in order to stimulate the economy. This is because the agents are forward-looking and internalize that the large increase in spending is going to be financed by higher taxes. In fact, in response to the government spending stimulus alone, the consumption multiplier is negative starting mid 2010, because of households anticipating expenditures financed by higher taxes. It is also clear that this fiscal expansion comes with a large increase in the level of debt, which remains above steady state for many years.

While the government purchases path is taken from Cogan, Cwik, Taylor, and Wieland (2009), the impact on GDP of the fiscal stimulus package are found to be larger than the ones reported in their paper. Focusing only on the effects of government spending, Cogan, Cwik, Taylor, and Wieland (2009) find the effects on GDP maximized in 2010, and that is an increase in GDP of close to $0.5 \%$ (as shown in Figure 2 of their paper). However, the estimated model predicts GDP rising by as much as $0.78 \%$ due to increased spending alone, in late 2010 . These differences arise because Cogan, Cwik, Taylor, and Wieland (2009) compute the impact on GDP based on spending multipliers from the estimated DSGE model of Smets and Wouters (2007), which are smaller than the ones estimated in this paper. Unlike the model of fiscal policy in this paper, in Smets and Wouters (2007), spending is financed by lump-sum taxes and the primary effects of 
increased government spending are negative wealth effects experienced by the households, resulting in a significant crowding out of both private consumption and investment. They do not consider a transmission mechanism for government spending and thus produce an empirically counterfactual large negative response of consumption to a positive spending shock.

One caveat to note in this analysis is that this has not taken into account that the role of monetary policy under current circumstances is limited as the Fed has recently been holding the nominal interest rate near zero.

In addition, since the model has a feedback from output to government spending, some of the changes in spending might be attributed to automatic stabilizers and would not be a shock. It is important to notice though that the countercyclical component of government spending is estimated to be rather small. To verify whether automatic stabilizers are significant in this case, I simulate government spending for 2009:1, using data on GDP and spending in 2008, and do not find evidence of larger deviations of government spending from steady state relative to 2008. This suggests that the extraordinary increase in government spending introduced in the stimulus package is in fact discretionary fiscal policy.

\section{Conclusion}

This paper provides evidence on the effects of fiscal policy actions in the context of a model featuring distortionary tax rates and rich fiscal rules, estimated using detailed fiscal data on tax rates, spending and debt.

I find that government spending has a large stimulative effect on impact, which decreases significantly at longer horizons. Tax cuts, on the other hand are always less stimulative in the short-run but their effects build over time. In particular, the impact multiplier for government spending is 1.12 and the estimated model predicts a positive response of private consumption to government spending, which is in contrast to models that do not consider a channel of transmission of government spending shocks, but is consistent with empirical studies. The multipliers for labor and capital tax on impact are 0.13 and 0.33 respectively, which exceed the stimulative effects of increased spending at horizons of 12-20 quarters. These effects of tax shocks are primarily driven by the response of investment.

In addition, counterfactual exercises reveal that the speed at which government debt is retired following a fiscal shock has consequences for the stimulative effect of the fiscal policy action, and these are most important at longer-run horizons. Also, although governments might rely on discretionary fiscal policy to stimulate the economy in the short-run, there are long lasting dynamics and the short-run effects can sharply differ from long-run effects of a fiscal policy action.

While assessing the role of monetary policy, I find that the response of the monetary authority to deviations of output from the steady state is significantly important in determining the movements of the real interest rate. This in turn, through intertemporal effects, has consequences for the size of fiscal multipliers. In fact, if the monetary authority reacts strongly to the state of the 
economy, then it limits the stimulative effects of increased government spending. Conversely, an accommodative monetary results in a higher fiscal multipliers for increased spending. However, less responsive monetary policy does not imply a larger stimulative effect in the case of all fiscal measures, as shown in the case of labor tax cuts. 


\section{Appendix}

\subsection{Complete Set of Symmetric Equilibrium Conditions}

$$
\begin{aligned}
& x_{t}^{c}=c_{t}-b^{c} s_{t-1}^{C} \\
& x_{t}^{g}=g_{t}-b^{g} s_{t-1}^{G} \\
& k_{t+1}=(1-\delta) k_{t}+i_{t}\left[1-\mathcal{S}\left(\frac{i_{t}}{i_{t-1}}\right)\right] \\
& d_{t} U_{x}\left(x_{t}^{c}, h_{t}\right)=\lambda_{t} \\
& -d_{t} U_{h}\left(x_{t}^{c}, h_{t}\right)=\frac{\lambda_{t} w_{t}}{\tilde{\mu}_{t}} \\
& \lambda_{t} q_{t}=\beta E_{t} \lambda_{t+1}\left[\left(1-\tau_{t+1}^{k}\right) r_{t+1}^{k} u_{t+1}-a\left(u_{t+1}\right)+q_{t+1}(1-\delta)+\delta q_{t+1} \tau_{t+1}^{k} u_{t+1}\right] \\
& \lambda_{t}=\lambda_{t} q_{t}\left[1-\mathcal{S}\left(\frac{i_{t}}{i_{t-1}}\right)-\left(\frac{i_{t}}{i_{t-1}}\right) \mathcal{S}^{\prime}\left(\frac{i_{t}}{i_{t-1}}\right)\right]+\beta E_{t} \lambda_{t+1} q_{t+1}\left(\frac{i_{t+1}}{i_{t}}\right)^{2} \mathcal{S}^{\prime}\left(\frac{i_{t+1}}{i_{t}}\right) \\
& \left(1-\tau_{t}^{k}\right) r_{t}^{k}+\delta q_{t} \tau_{t}^{k}=a^{\prime}\left(u_{t}\right) \\
& (\tilde{\eta}-1)\left(1-\tau_{t}^{w}\right) h_{t}+\tilde{\alpha} \pi_{t}^{w}\left(\pi_{t}^{w}-\bar{\pi}\right)-\tilde{\eta} \frac{h_{t}}{\tilde{\mu}_{t}}=\tilde{\alpha} \beta E_{t}\left[\frac{\lambda_{t+1}}{\lambda_{t}} \pi_{t+1}^{w}\left(\pi_{t+1}^{w}-\bar{\pi}\right)\right] \\
& \lambda_{t}=\beta R_{t} E_{t} \frac{\lambda_{t+1}}{\pi_{t+1}}, \\
& \frac{1-m c_{t}-\tilde{\nu}_{t}^{c}}{\theta^{c}-1}=\beta E_{t} \frac{\lambda_{t+1}}{\lambda_{t}}\left[b^{c} \tilde{\nu}_{t+1}^{c}+\frac{\theta^{c}}{\theta^{c}-1}\left\{1-m c_{t+1}-\tilde{\nu}_{t+1}^{c}\right\}\right] \\
& \frac{1-m c_{t}-\tilde{\nu}_{t}^{g}}{\theta^{g}-1}=\beta E_{t} \frac{\lambda_{t+1}}{\lambda_{t}}\left[b^{g} \widetilde{\nu}_{t+1}^{g}+\frac{\theta^{g}}{\theta^{g}-1}\left\{1-m c_{t+1}-\tilde{\nu}_{t+1}^{g}\right\}\right] \\
& 1-m c_{t}-\tilde{\nu}_{t}^{i}=0 \\
& \eta\left(\tilde{\nu}_{t}^{c} x_{t}^{c}+\tilde{\nu}_{t}^{g} x_{t}^{g}+\tilde{\nu}_{t}^{i}\left(y_{t}-c_{t}-g_{t}\right)\right)+\alpha \pi_{t}\left(\pi_{t}-\bar{\pi}\right)-y_{t}=\alpha \beta E_{t}\left[\frac{\lambda_{t+1}}{\lambda_{t}} \pi_{t+1}\left(\pi_{t+1}-\bar{\pi}\right)\right] \\
& z_{t} F\left(u_{t} k_{t}, h_{t}\right)-\psi=c_{t}+g_{t}+i_{t}+a\left(u_{t}\right) k_{t}+\frac{\alpha}{2}\left(\pi_{t}-\pi\right)^{2}+\frac{\tilde{\alpha}}{2}\left(\pi_{t}^{w}-\bar{\pi}\right)^{2} w_{t} \\
& y_{t}=z_{t} F\left(u_{t} k_{t}, h_{t}\right)-\psi-\frac{\alpha}{2}\left(\pi_{t}-\pi\right)^{2} \\
& \mathrm{mc}_{t} z_{t} F_{2}\left(u_{t} k_{t}, h_{t}\right)=w_{t} \\
& \mathrm{mc}_{t} z_{t} F_{1}\left(u_{t} k_{t}, h_{t}\right)=r_{t}^{k} \\
& b_{t}=R_{t-1} \frac{b_{t-1}}{\pi_{t}}+g_{t}+t r_{t}-\tau_{t} \\
& \tau_{t}=\tau_{t}^{w} w_{t} h_{t}+\tau_{t}^{k}\left(r_{t}^{k} u_{t} k_{t}-\delta q_{t} u_{t} k_{t}\right) \\
& s_{t}^{C}=\theta^{c} s_{t-1}^{C}+\left(1-\theta^{c}\right) c_{t} \\
& s_{t}^{G}=\theta^{g} s_{t-1}^{G}+\left(1-\theta^{g}\right) g_{t}
\end{aligned}
$$


and equations (2), (8), (13), (14), (15), (16), (17) and (19) from the text.

\subsection{Steady State}

$$
\begin{aligned}
& q=1, u=1 \\
& R=\frac{\pi}{\beta} \\
& r^{k}=\left(\frac{1}{\beta}-1+\delta-\delta \tau^{k}\right) /\left(1-\tau^{k}\right) \\
& \text { share }_{i}=I / Y=\delta \theta / r^{k} \\
& \text { share }^{c}=C / Y=1-\text { share }^{i}-\text { share }^{g} \\
& \gamma_{1}=\left(1-\tau^{k}\right) r^{k}+\delta \tau^{k}, \gamma_{2}=\sigma^{u} \gamma_{1} \\
& \tilde{\mu}=\frac{\tilde{\eta}}{(\tilde{\eta}-1)\left(1-\tau^{w}\right)} \\
& m c=\frac{\operatorname{share}^{c}+\operatorname{share}^{i}+\operatorname{share}^{g}}{\eta\left(\operatorname{share}^{c} a a^{c} / b b^{c}+\operatorname{share}^{g} a a^{g} / b b^{g}-\text { share }^{i}\right)}+1 \\
& a a^{c}=\left(1-b^{c}\right), b b^{c}=\left(\beta b^{c}\left(\theta^{c}-1\right)\right) /\left(\beta \theta^{c}-1\right)-1 \\
& a a^{g}=\left(1-b^{g}\right), b b^{g}=\left(\beta b^{g}\left(\rho^{g}-1\right)\right) /\left(\beta \rho^{g}-1\right)-1 \\
& \nu^{c}=(m c-1) / b b c, \nu^{g}=(m c-1) / b b g, \nu^{i}=(m c-1) \\
& K=\left(r^{k} / m c / \theta\right)^{\frac{1}{\theta-1}} H \\
& I=\delta K \\
& w=m c(1-\theta)(K / H)^{\theta} \\
& \psi=K^{\theta} H^{1-\theta}-\left(r^{k} K+w H\right) \\
& Y=K^{\theta} H^{1-\theta}-\psi \\
& s^{c}=C, s^{g}=G \\
& a=(1-h) w /\left((1-H) w+\tilde{\mu}\left(C-b^{c} s^{c}\right)\right) \\
& \lambda=(1-a)\left(c\left(1-b^{c}\right)\right)^{(1-a)(1-\sigma)-1}(1-h)^{a(1-\sigma)} \\
& \tau=\tau^{w} w H+\tau^{k}\left(r^{k}-\delta\right) K \\
& t r=b\left(1-\frac{R}{\pi}\right)-G+\tau
\end{aligned}
$$




\subsection{Data used in estimation}

The following quarterly series were used in the estimation. In order to construct real per-capita values, GDP deflator (given by Table 1.1.6, Line 1) and civilian non-institutional population, over 16 (given by LNU00000000Q, at Bureau of Labor Statistics) are used. The table and line numbers refer to the NIPA tables on the Bureau of Economic Analysis website. The data for consumption, investment, government spending and debt were linearly detrended to get stationary series.

- Consumption: Sum of personal consumption expenditures on non-durables goods (Table 1.1.5, Line 3) and services (Table 1.1.5, Line 5) divided by the GDP deflator and by population.

- Inflation: First difference of GDP deflator.

- Federal funds rate: Monthly federal funds rate series from St. Louis FRED website was averaged to create quarterly series.

- Investment: Sum of gross private domestic investment (Table 1.1.5, Line 6) and personal consumption expenditures on nondurable goods (Table 1.1.5, Line 4), divided by the GDP deflator and by population.

- Government spending: Government consumption expenditures and gross investment (Table 1.1.5, Line 20) divided by the GDP deflator and by population.

- Debt: Market value of federal debt held by public from the Dallas Fed website divided by the GDP deflator and by population. The quarterly series is constructed by summing up the monthly series. The series of debt initialized by the Dallas Fed series and constructed from secondary deficit data from NIPA matches up in levels and the correlation is 0.99.

- Capital and labor tax rate: The method of Jones (2002) was used to construct these series. The first step is to construct the average personal income tax rate,

$$
\tau_{p}=\frac{F I T+S I T}{W+P R I / 2+C I}
$$

where FIT denotes federal income taxes (Table 3.2, Line 3), SIT denotes state and local income taxes (Table 3.3, Line 3), $W$ denotes wages and salaries (Table 1.12, Line 3), PRI denotes proprietor's income (Table 1.12, Line 9) and $C I$ denotes capital income which is the sum of rental income (Table 1.12, Line 12), corporate profits (Table 1.12, Line 13), net interest (Table 1.12, Line 18) and $P R I / 2$. The labor tax rate, $\tau^{w}$, is then calculated as,

$$
\tau^{w}=\frac{\tau^{p}[W+P R I / 2]+C S I}{E C+P R I / 2}
$$

where $C S I$ is total contributions to government social insurance (Table 3.1, Line 7) and EC denotes total compensation of employees (Table 1.12, Line 2). The capital tax rate, $\tau^{k}$ is calculated as,

$$
\tau^{k}=\frac{\tau^{p} C I+C T+P T}{C T+P T}
$$

The tax rates are constructed as average tax rates using the methodology in Mendoza, Razin, and Tesar (1994) and Jones (2002), primarily because they are easily constructed on a quarterly basis using data on actual tax payments and national accounts, and in addition allow 
us to distinguish between taxes on labor and capital income. Other tax rate series include Barro and Sahasakul (1983) marginal tax rate series on personal income, where they average tax rates over the number of returns for each class of adjusted gross income. However, this does not differentiate between tax rates on capital and labor income. McGrattan (1994) linearly interpolates annual tax rates constructed following Joines (1981) to obtain quarterly observations. The main difference between Jones (2002) and their tax rate series is that they estimate the personal income tax rate as a marginal tax rate from tax records, rather than as an average rate from the national accounts. While much easier to construct, Mendoza, Razin, and Tesar (1994) show that average tax rates in different countries tend to follow the same dynamics as marginal tax rates. ${ }^{34}$

\subsection{Multipliers Implied by the Priors}

To evaluate the economic content of the priors of the parameters being estimated, Table 6 shows their implications for the fiscal multipliers, that are the focus of the paper. The table reports the median and 95 percentile present value multipliers for 500 random draws from the prior distribution of the parameters. Since deep habits are introduced as a transmission mechanism, notice that the median impact multiplier for government spending is larger than 1. However, as the confidence bands illustrate that the priors do not exclude the possibility of a much smaller spending multiplier. In general, tax multipliers are smaller than spending multiplier at early horizons. Also, note that the confidence bands are large, particularly for longer horizons, which reflects the disperse priors for fiscal rule parameters.

Table 6: Present Value Multipliers Implied by the Priors

\begin{tabular}{|c|c|c|c|c|}
\hline \multicolumn{5}{|c|}{ Government Spending Multiplier } \\
\hline & Quarter 1 & Quarter 4 & Quarter 12 & Quarter 20 \\
\hline$\frac{P V \Delta Y_{t+k}}{P V \Delta G_{t+k}}$ & $\begin{array}{c}1.06 \\
{[0.7,1.8]}\end{array}$ & $\begin{array}{c}0.93 \\
{[0.5,1.9]}\end{array}$ & $\begin{array}{c}0.41 \\
{[-0.2,1.7]}\end{array}$ & $\begin{array}{c}0.12 \\
{[-0.65,1.4]}\end{array}$ \\
\hline \multicolumn{5}{|c|}{ Labor Tax Multiplier } \\
\hline & Quarter 1 & Quarter 4 & Quarter 12 & Quarter 20 \\
\hline \multirow{4}{*}{$\frac{P V \Delta Y_{t+k}}{P V \Delta T_{t+k}^{w}}$} & 0.10 & 0.22 & 0.40 & 0.25 \\
\hline & {$[0.0,0.3]$} & {$[0.0,0.5]$} & {$[-1.0,0.9]$} & {$[-6.2,1.5]$} \\
\hline & \multicolumn{3}{|c|}{ Capital Tax Multiplier } & \\
\hline & Quarter 1 & Quarter 4 & Quarter 12 & Quarter 20 \\
\hline \multirow{2}{*}{$\frac{P V \Delta Y_{t+k}}{P V \Delta T_{t+k}^{k}}$} & 0.45 & 0.61 & 0.73 & 0.59 \\
\hline & {$[0.3,0.8]$} & {$[0.3,1.1]$} & {$[-0.3,1.6]$} & {$[-5.0,1.9]$} \\
\hline
\end{tabular}

Note: This table shows the present discounted value of the cumulative change in output over the present value cumulative change in the fiscal variable of interest, over the $k$ quarters, for 500 random draws from the prior distribution of the parameters. The reported numbers are the median multipliers and the 95 percentiles are given below in brackets.

\footnotetext{
${ }^{34}$ Following Jones (2002), since the labor tax rate series has a trend and its idiosyncratic with no counterpart in the model, it is removed by linearly detrending the series. Mendoza, Razin, and Tesar (1994) also show that in many different countries, the capital tax series is stationary but the labor tax series has an upward trend.
} 
Table 7: Moment Comparison

\begin{tabular}{|c|c|c|c|}
\hline & \multirow[t]{2}{*}{ Data } & \multicolumn{2}{|c|}{ Model } \\
\hline & & Median & {$[5,95]$} \\
\hline Std. Dev. of Output (\%) & 3.62 & 4.65 & {$[3.24,5.31$} \\
\hline \multicolumn{4}{|c|}{ Standard Deviation/ Standard Deviation of Output } \\
\hline Consumption & 0.83 & 0.86 & {$[0.77,0.97$} \\
\hline Investment & 2.94 & 4.50 & {$[3.19,5.64$} \\
\hline Inflation & 0.16 & 0.18 & {$[0.13,0.21$} \\
\hline Nominal Interest Rate & 0.87 & 0.52 & {$[0.32,0.74$} \\
\hline Government Spending & 1.41 & 0.85 & {$[0.64,1.18$} \\
\hline Capital tax rate & 0.89 & 1.13 & {$[0.70,1.88$} \\
\hline Labor tax rate & 0.45 & 0.83 & {$[0.41,1.01$} \\
\hline Hours & 1.02 & 1.15 & {$[0.74,1.70$} \\
\hline
\end{tabular}

For randomly chosen 1000 draws, I generate 500 samples of the observable series implied by the model with the same length as the data-set (204 observations) after discarding the first 80 initial observations. The table reports the median and 5th and 95th percentile together with the corresponding moment in the data.

\subsection{Fit of the Model}

In order to assess the goodness of fit of the model, Figure 13 shows the data used in the estimation, along with the posterior mean of the smoothed series implied by the estimated model. The fit of the model is nearly perfect for most variables, notably government spending and tax rates. The model predicts consumption relatively smoother than is observed. The only significant discrepancy is inflation where the model implies less overall volatility.

Table 7 also reports the standard deviations computed from data and those implied by the model. It also reports the 90 percent probability intervals that account for both parameter uncertainty and small sample uncertainty. Relative to the data, the model over-predicts the standard deviation of output a little, and approximately matches the relative standard deviation of consumption, inflation and hours. There is some tendency to over-predict the volatility of investment, and tax rates and under predict the volatility of nominal interest rate and government spending. Note that the estimated model does not perfectly match these moments, since I am employing a likelihood based estimation procedure, which tries to match the entire structure of the data series, including second moments, autocorrelations and cross-correlations.

Figure 14 shows the autocorrelations and cross-correlations generated by the model and in the data for selected observable variables. The model predictions are the black lines, where the solid black line is the median and the dashed lines are the 90 percent posterior intervals. The data is represented by the grey lines. The diagonal of the figure shows that the model is able to capture the decaying autocorrelation structure of the variables quite well. Generally, the data cross-correlations fall within the confidence bands. These error bands, however, are quite large, accounting for both parameter and small sample uncertainty. 
Figure 13: Model fit
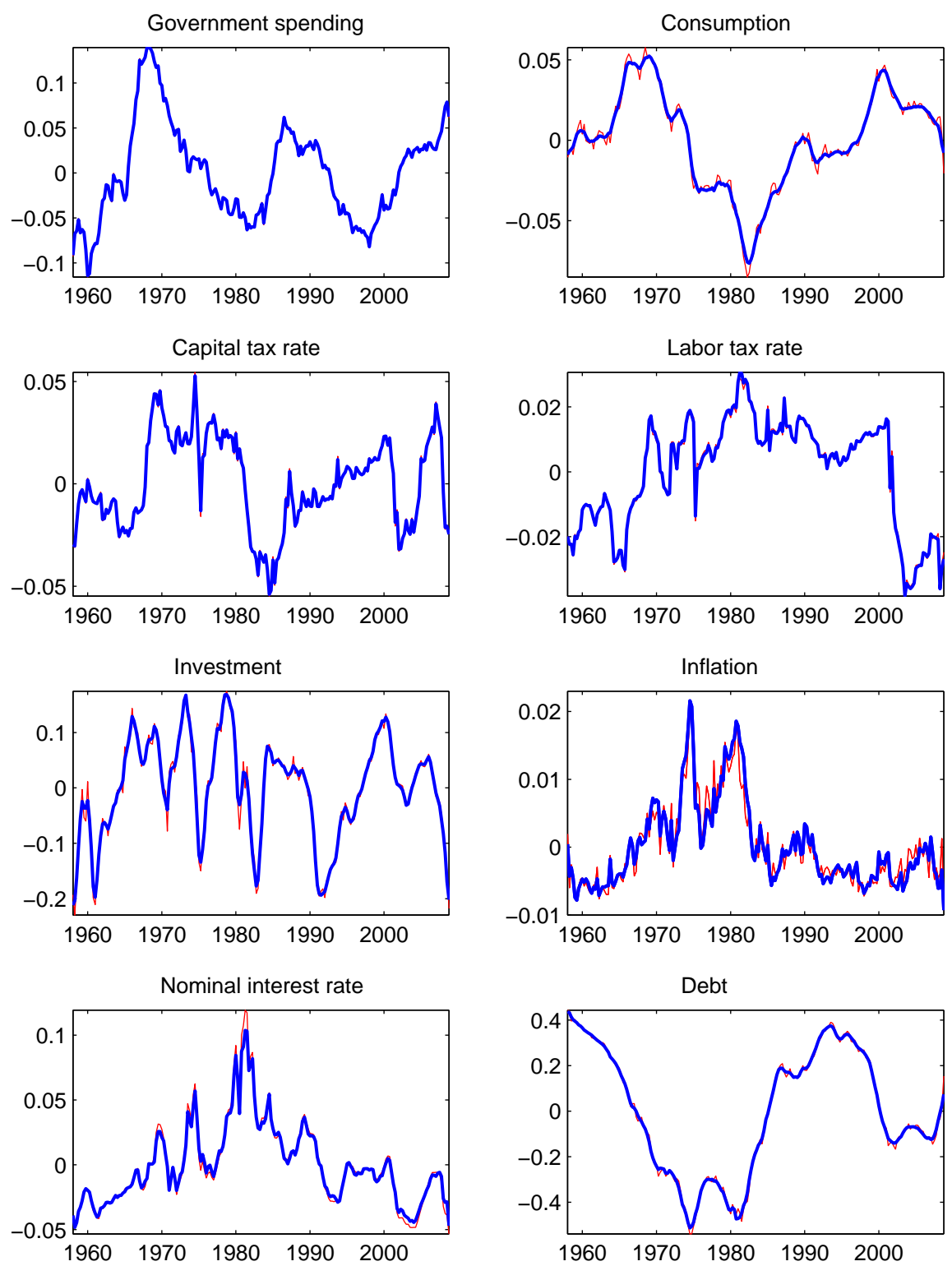

Note: The thin red line is the data used in the estimation and the thick blue line is posterior mean of the smoothed version of the same series. 
Figure 14: Cross-correlations
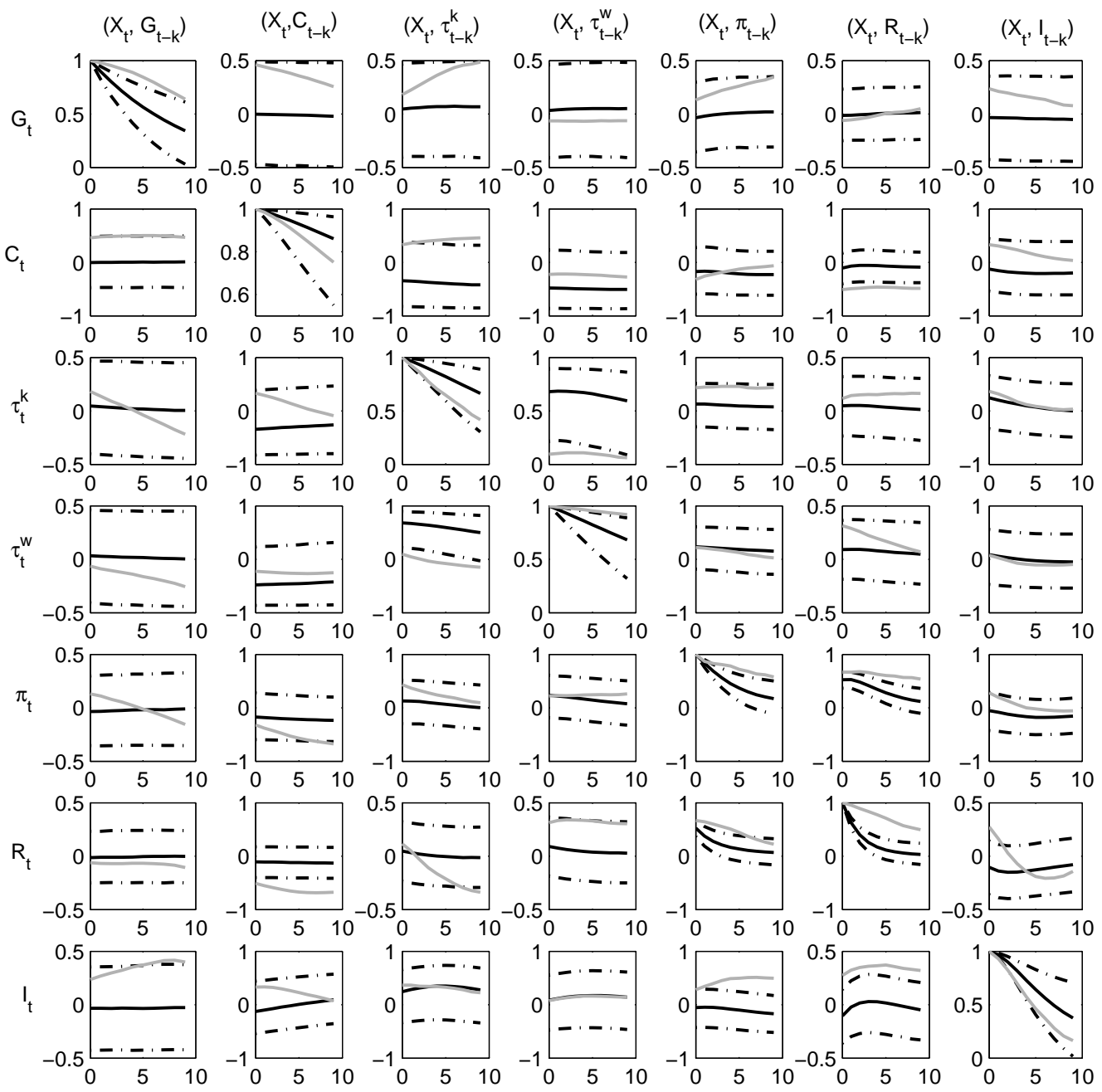

Note: The black line represent the median cross-correlations implied by the model along with the $90 \%$ confidence bands (dash-dotted line). The grey lines are the data cross-correlations. Each column gives the correlation between $X_{t}$ and the variable specified, where $X_{t}$ is given in each row. The $\mathrm{x}$-axis gives the values of $k$. 


\subsection{Model Comparison to Alternative Specification of Fiscal Rules}

I compare the baseline model with the processes for government spending and transfers given by Equations (15) and (16), with one where both government spending and transfers have exogenous $\mathrm{AR}(1)$ processes and do not respond to the state of the economy (so that $\rho_{g, y}=\rho_{t r, y}=0$ ). Exogenous processes for fiscal variables, especially government spending are a common assumption in the literature.

I also compare the baseline model to the case where the government spending process is given by Equation (15) but I allow transfers to additionally respond to the level of lagged debt, so that the process for transfers, instead of Equation (16), is given by,

$$
\hat{t r}_{t}=\rho_{t r} \hat{t r}_{t-1}+\rho_{t r, y} \hat{y}_{t-1}+\rho_{t r, b} \hat{b}_{t-1}+\epsilon_{t}^{t r} .
$$

In order to compare the estimated baseline model with different specifications of fiscal rules, I report the log marginal likelihood for two alternative models relative to the baseline model, in Table 8. These were computed using the modified harmonic mean proposed by Geweke (1999). According to this criterion, eliminating any feedback from the economy to government spending and transfers worsens the fit of the model, even though the marginal likelihood penalizes over-parametrization. The log marginal likelihood difference between the baseline case and allowing transfers to respond to the level of debt, in addition to the tax rates, is close to three. As argued in Rabanal and RubioRamirez (2005), this difference cannot be accepted as decisive evidence in favor of one model over the other.

Table 8: Model Comparison

\begin{tabular}{lc}
\hline \hline Specification & $\begin{array}{c}\text { Log Marginal Likelihood } \\
\text { (Difference from Baseline) }\end{array}$ \\
\hline Exogenous processes for $t r_{t}$ and $g_{t}$ & -63.5 \\
Also allow $t r_{t}$ to respond to $b_{t-1}$ & 3.1 \\
\hline \hline
\end{tabular}

Note: The table shows the log marginal likelihood for different model specifications minus that for the baseline model. 


\section{References}

Altig, D., L. Christiano, M. Eichenbaum, and J. Linde (2005): "Firm-Specific Capital, Nominal Rigidities and the Business Cycle," Discussion paper, NBER.

Aschauer, D. A. (1985): "Fiscal Policy and Aggregate Demand," American Economic Review, $75(1), 117-27$.

Baxter, M., And R. G. King (1993): "Fiscal Policy in General Equilibrium," American Economic Review, 83(3), 315-34.

BILs, M. (1987): "The Cyclical Behavior of Marginal Cost and Price," American Economic Review, $77(5), 838-55$.

Blanchard, O., and R. Perotti (2002): "An Empirical Characterization Of The Dynamic Effects Of Changes In Government Spending And Taxes On Output," The Quarterly Journal of Economics, 117(4), 1329-1368.

Braun, A. R. (1994): "Tax Disturbances and Real Economic Activity in the Postwar United States," Journal of Monetary Economics, 33(3), 441-462.

Burnside, C., M. Eichenbaum, and J. D. M. Fisher (2004): "Fiscal shocks and their Consequences," Journal of Economic Theory, 115(1), 89-117.

Christiano, L., M. Eichenbaum, and S. Rebelo (2009): "When is the Government Spending Multiplier Large?," Manuscript, Northwestern University.

Christiano, L. J., M. Eichenbaum, and C. L. Evans (2005): "Nominal Rigidities and the Dynamic Effects of a Shock to Monetary Policy," Journal of Political Economy, 113(1), 1-45.

Chung, H., and E. Leeper (2007): "What Has Financed Government Debt?" Discussion paper, NBER Working Paper.

Clarida, R., J. Gali, and M. Gertler (2000): "Monetary Policy Rules And Macroeconomic Stability: Evidence And Some Theory," The Quarterly Journal of Economics, 115(1), 147-180.

Coenen, G., and R. Straub (2005): "Does Government Spending Crowd in Private Consumption? Theory and Empirical Evidence for the Euro Area," International Finance, 8(3), 435-470.

Cogan, J. F., T. Cwik, J. B. Taylor, and V. Wieland (2009): "New Keynesian versus Old Keynesian Government Spending Multipliers," Discussion paper, NBER Working Paper.

Corsetti, G., A. Meier, And G. J. Muller (2009): "Fiscal Stimulus with Spending Reversals," Discussion paper, C.E.P.R. Discussion Papers.

Davig, T., And E. M. Leeper (2009): "Monetary-Fiscal Policy Interactions and Fiscal Stimulus," Discussion paper, NBER Working Paper.

Del-Negro, M., F. Schorfheide, F. Smets, and R. Wouters (2005): "On the Fit and Forecasting Performance of New-Keynesian models," Discussion paper, ECB Working Paper.

Edelberg, W., M. Eichenbaum, and J. D. Fisher (1999): "Understanding the Effects of a Shock to Government Purchases," Review of Economic Dynamics, 2(1), 166-206. 
Eggertsson, G. (2009): "Can Tax Cuts Deepen Recessions?," Manuscript, Federal Reserve Bank of New York.

Fatas, A., And I. Minov (2001): "The Effects of Fiscal Policy on Consumption and Employment: Theory and Evidence," Discussion paper, C.E.P.R. Discussion Papers.

Favero, C., And F. Giavazzi (2007): "Debt and the Effects of Fiscal Policy," Discussion paper, NBER Working Paper.

Forni, L., L. Monteforte, And L. Sessa (2009): "The General Equilibrium Effects of Fiscal Policy: Estimates for the Euro area," Journal of Public Economics, 93(3-4), 559-585.

Gali, J., M. Gertler, and J. D. Lopez-Salido (2007): "Markups, Gaps, and the Welfare Costs of Business Fluctuations," The Review of Economics and Statistics, 89(1), 44-59.

Gali, J., J. D. Lopez-Salido, and J. Valles (2007): "Understanding the Effects of Government Spending on Consumption," Journal of the European Economic Association, 5(1), 227-270.

Geweke, J. (1999): "Using Simulation Methods for Bayesian Econometric Models: Inference, Development,and Communication," Econometric Reviews, 18(1), 1-73.

Joines, D. H. (1981): "Estimates of Effective Marginal Tax Rates on Factor Incomes," Journal of Business, 54(2), 191-226.

Jones, J. B. (2002): "Has Fiscal Policy Helped Stabilize the Postwar U.S. Economy?," Journal of Monetary Economics, 49(4), 709-746.

Leeper, E. M. (1991): "Equilibria Under 'Active' and 'Passive' Monetary and Fiscal Policies," Journal of Monetary Economics, 27(1), 129-147.

Leeper, E. M., M. Plante, and N. Traum (2009): "Dynamics of Fiscal Financing in the United States," Discussion paper, NBER Working Paper.

Leeper, E. M., T. B. Walker, and S.-C. S. Yang (2008): "Fiscal Foresight: Analytics and Econometrics," Discussion paper, NBER Working Paper.

Paper.

(2009): "Fiscal Foresight and Information Flows," Discussion paper, NBER Working

Linnemann, L., And A. Schabert (2003): "Fiscal Policy in the New Neoclassical Synthesis," Journal of Money, Credit and Banking, 35(6), 911-29.

Lopez-Salido, D., and P. Rabanal (2006): "Government Spending and Consumption-Hours Preferences," Discussion paper, la Caixa Working Papers.

McGrattan, E. R. (1994): "The Macroeconomic Effects of Distortionary Taxation," Journal of Monetary Economics, 33(3), 573-601.

Mendoza, E. G., A. Razin, and L. L. Tesar (1994): "Effective Tax Rates in Macroeconomics: Cross-Country Estimates of Tax Rates on Factor Incomes and Consumption," Journal of Monetary Economics, 34(3), 297-323.

Mertens, K., And M. O. Ravn (2008): "The Aggregate Effects of Anticipated and Unanticipated U.S. Tax Policy Shocks: Theory and Empirical Evidence," Discussion paper, C.E.P.R. Discussion Papers. 
Monacelli, T., and R. Perotti (2008): "Fiscal Policy, Wealth Effects, and Markups," Discussion paper, NBER Working Paper.

Mountford, A., And H. Uhlig (2002): "What are the Effects of Fiscal Policy Shocks?," Discussion paper, C.E.P.R. Discussion Papers.

NI, S. (1995): "An Empirical Analysis on the Substitutability between Private Consumption and Government Purchases," Journal of Monetary Economics, 36(3), 593-605.

Perotti, R. (2002): "Estimating the Effects of Fiscal Policy in OECD Countries," Working Paper 015, European Network of Economic Policy Research Institutes.

Rabanal, P., and J. F. Rubio-Ramirez (2005): "Comparing New Keynesian Models of the Business Cycle: A Bayesian Approach," Journal of Monetary Economics, 52(6), 1151-1166.

Ramey, V. (2008): "Identifying Government Spending Shocks: It's All in the Timing," Mimeo, UCSD.

Ramey, V. A., And M. D. Shapiro (1998): "Costly Capital Reallocation and the Effects of Government Spending," Carnegie-Rochester Conference Series on Public Policy, 48(1), 145-194.

Ravn, M., S. Schmitt-Grohe, and M. Uribe (2006): "Deep Habits," Review of Economic Studies, 73(1), 195-218.

(2007): "Explaining the Effects of Government Spending Shocks on Consumption and the Real Exchange Rate," Discussion paper, NBER Working Paper.

Romer, C., And J. Bernstein (2009): "The Job Impact of the American Recovery and Reinvestment Plan," Discussion paper, Obama Transition Team.

Romer, C. D., And D. H. Romer (2007): "The Macroeconomic Effects of Tax Changes: Estimates Based on a New Measure of Fiscal Shocks," Discussion paper, NBER Working Paper.

Rotemberg, J. J. (1982): "Sticky Prices in the United States," Journal of Political Economy, 90(6), 1187-1211.

Rotemberg, J. J., And M. Woodford (1999): "The Cyclical Behavior of Prices and Costs," in Handbook of Macroeconomics, ed. by J. B. Taylor, and M. Woodford.

Schmitt-Grohe, S., And M. Uribe (2004): "Solving Dynamic General Equilibrium Models using a Second-Order Approximation to the Policy Function," Journal of Economic Dynamics and Control, 28(4), 755-775.

— (2007): "Optimal Simple and Implementable Monetary and Fiscal Rules," Journal of Monetary Economics, 54(6), 1702-1725.

Smets, F., And R. Wouters (2007): "Shocks and Frictions in US Business Cycles: A Bayesian DSGE Approach," American Economic Review, 97(3), 586-606.

Uhlig, H. (2009): "Some Fiscal Calculus," Manuscript, University of Chicago.

Zubairy, S. (2009): "Explaining the Effects of Government Spending Shocks," Manuscript, Duke University. 